\title{
ATIVAÇÃO DA VIA DE SINALIZAÇÃO NOTCH PELOS ONCOGENES RET/PTC E BRAFT1799A NO CARCINOMA PAPILÍFERO DE TIROIDE E SUA INFLUÊNCIA NA DIFERENCIAÇÃO E PROLIFERAÇÃO CELULAR
}

Tese apresentada ao Programa de PósGraduação em Biologia Celular e Tecidual do Instituto de Ciências Biomédicas da Universidade de São Paulo, para obtenção do Título de Doutor em Ciências. 


\section{ATIVAÇÃO DA VIA DE SINALIZAÇÃO NOTCH PELOS ONCOGENES RET/PTC E BRAFT1799A NO CARCINOMA PAPILÍFERO DE TIROIDE E SUA INFLUÊNCIA NA DIFERENCIAÇÃO E PROLIFERAÇÃO CELULAR}

Tese apresentada ao Programa de PósGraduação em Biologia Celular e Tecidual do Instituto de Ciências Biomédicas da Universidade de São Paulo, para obtenção do Título de Doutor em Ciências.

Área de concentração: Biologia Celular e Tecidual

Orientadora: Profa. Dra. Edna Teruko Kimura

Versão corrigida. A versão original eletrônica encontra-se disponível tanto na Biblioteca do ICB quanto na Biblioteca Digital de Teses e Dissertações da USP (BDTD). 
DADOS DE CATALOGAÇÃO NA PUBLICAÇÃO (CIP)

Serviço de Biblioteca e Informação Biomédica do

Instituto de Ciências Biomédicas da Universidade de São Paulo

reprodução não autorizada pelo autor

Yamashita, Alex Shimura.

Ativação da via de sinalização Notch pelos oncogenes RET/PTC e $B R A F T 1799 A$ no carcinoma papilífero de tiroide e sua influência na diferenciação e proliferação celular / Alex Shimura Yamashita. -- São Paulo, 2013.

\section{Orientador: Profa. Dra. Edna Teruko Kimura.}

Tese (Doutorado) - Universidade de São Paulo. Instituto de Ciências Biomédicas. Departamento de Biologia Celular e do Desenvolvimento. Área de concentração: Biologia Celular e Tecidual. Linha de pesquisa: Biologia Molecular da Tiroide.

Versão do título para o inglês: Notch signaling activation by RET/PTC and BRAFT1799A in papillary thyroid carcinoma and their influence in cell differentiation and proliferation.

1. Glândula tireóide 2. Neoplasias da tireóide 3. Oncoproteínas 4. Transdução de sinal celular I. Kimura, Profa. Dra. Edna Teruko

II. Universidade de São Paulo. Instituto de Ciências Biomédicas.

Programa de Pós-Graduação em Biologia Celular e Tecidual III. Título. 


\title{
UNIVERSIDADE DE SÃO PAULO INSTITUTO DE CIÊNCIAS BIOMÉDICAS
}

\begin{abstract}
Candidato(a):
Alex Shimura Yamashita.

Título da Tese:

Ativação da via de sinalização Notch pelos oncogenes RET/PTC e BRAFT1799A no carcinoma papilífero de tireoide e sua influência na diferenciação e proliferação celular.
\end{abstract}

Orientador(a):

Profa. Dra. Edna Teruko Kimura.

A Comissão Julgadora dos trabalhos de Defesa da Tese de Doutorado, em sessão pública realizada a ................., considerou

\section{( ) Aprovado(a)}

\section{( ) Reprovado(a)}

\begin{tabular}{|c|c|}
\hline Examinador(a): & Assinatura: \\
\hline & Nome: ........ \\
\hline & Instituição: ... \\
\hline Examinador(a): & Assinatura: . \\
\hline & Nome: ......... \\
\hline & Instituição: ....... \\
\hline Examinador(a): & Assinatura: ....... \\
\hline & Nome: ........... \\
\hline & Instituição: ...... \\
\hline Examinador(a): & Assinatura: ... \\
\hline & Nome: ........... \\
\hline & Instituição: ......................... \\
\hline Presidente: & Assinatura: . \\
\hline & Nome: ......... \\
\hline & Instituição: \\
\hline
\end{tabular}




\section{CERTIFICADO DE ISENÇÃO}

Certificamos que o Protocolo CEP-ICB No 365/10 referente ao projeto intitulado: "Papel do cross-talk das vias de sinalização TGF- $\beta$ e NOTCH na ativação oncogênica na célula folicular tiroidiana" sob a responsabilidade de Alex Shimura Yamashita, foi analisado na presente data pela CEUA - COMISSÃO DE ÉTICA NO USO DE ANIMAIS e pela CEPSHCOMissão de Ética EM PESquisa COM seres humanos, tendo sido deliberado que o referido projeto não envolve manipulação animal ou humana que justifique uma aprovação quanto aos princípios éticos exigidos por ambas as Comissões.

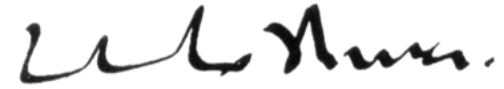

PROF. DR. WOTHAN TAVARES DE LIMA Coordenador da CEUA - ICB/USP
São Paulo, 30 de março de 2010.

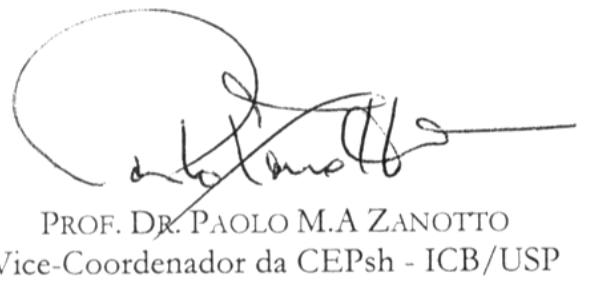




\section{UNIVERSIDADE DE SÃO PAULO INSTITUTO DE CIÊNCIAS BIOMÉDICAS}

Cidade Universitária "Armando de Salles Oliveira"

Av. Prof. Lineu Prestes, 2415 - CEP. 05508-000 São Paulo, SP - Brasil

Telefone :(55) (011) 3091.7733 - e-mail: cep(licb.usp.br

\section{Certificado}

Certificamos que o protocolo registrado sob $n^{\circ} 134$ nas fls. 93 do livro 02 para uso de animais em experimentação, sob a responsabilidade do Prof(a) Dr(a) Edna Teruko Kimura, Coordenador(a) da Linha de pesquisa MicroRNAs nos tumores de tiroide: influência na proliferação e ativação oncogênica da célula folicular tiroidiana do qual participam o(s) alunos Alex Shimura Yamashita, Ana Paula Zen Petisco Fiore, Cesar Seigi Fuziwara, Murilo Vieira Geraldo, Caio Henrique Bezerra Silva, Felipe Martins Elias, Luciana Machado Dzik, Marcelo Costa e Silva, está de acordo com os Principios Éticos de Experimentaçāo Animal adotado pela Sociedade Brasileira de Ciência de Animais de Laboratório (SBCAL) e foi aprovado pela COMISSÃO DE ÉTICA NO USO DE ANIMAIS (CEUA) em 29.10.2010, com validade de 3 anos.
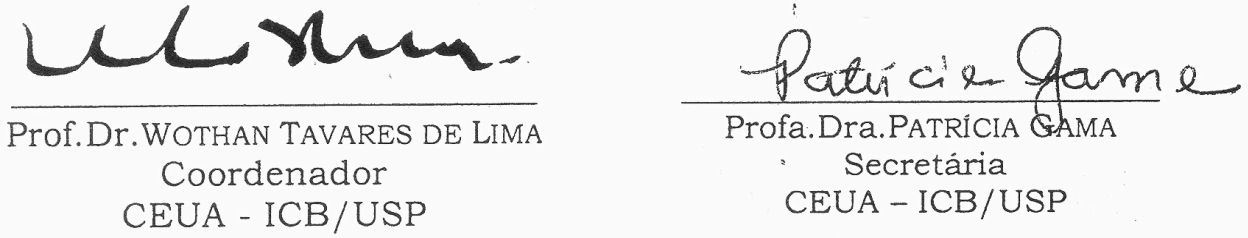




UNIVERSIDADE DE SÃO PAULO

INSTITUTO DE CIÊNCIAS BIOMÉDICAS

Cidade Universitária "Armando de Salles Oliveira"

Av. Prof. Lineu Prestes, 2415 - cep. 05508-000 Săo Paulo, SP - Brasil

Telefone :(55) (011) 3091.7733 - telefax : (55) (011) 30917438

e-mail: cep@icb.usp.br

Of.CEPSH.250.09

$\mathrm{PMAZ} / \mathrm{mcgn}$

i

São Paulo, 27 de outubro de 2009.

Prezada Senhora,

A Comissão de Ética em Pesquisa com Seres Humanos em sessão de 23.10.09, deliberou a autorização para o cadastro da teca referente ao material de origem humana do Projeto: "Controle da proliferação da célula folicular da tiróide e câncer"

Informo que o material poderá ser utilizado em novas pesquisa desde que aprovada pela Comissão de Ética deste Instituto.

Atenciosamente,

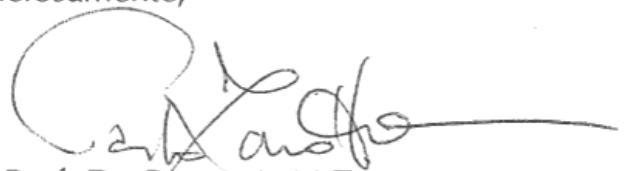

Prof. Dr. PÁlo A. M.ZAnotto

Vice Coordenador da Comissão de Ética em

Pesquisas com Seres Humanos - ICB /USP

Ilma. Sra.

Profa. Dra. EDNA TeRUKO KIMURA

Departamento de Biologia Celular e do Desenvolvimento

Instituto de Ciências Biomédicas da USP

Comissão de Ética em Pesquisa com Seres Humanos do Instituto de Ciências Biomédicas / USP Aprovada pela Comissão Nacional de Ética em Pesquisa - CONEP, em 10 de fevereiro de 1998. 
Aos meus pais, Ismael e Isaura, e meus irmãos André e Adriana. 
À minha Marina, pelo carinho, amor e cumplicidade. 


\section{AGRADECIMENTOS}

À Dra. Edna Teruko Kimura pelos ensinamentos e por contribuir com meu aprimoramento científico.

Aos amigos do Laboratório de Biologia Molecular da Glândula Tiroide, Ana Zen, Luciane Dzik, Luciane Martins, Eloiza Resende, Kellen, Sabrina, Marley, Aline Olivé, Júlio Ricarte-Filho, Caio Bezerra e Felipe Martins.

Ao César Fuziwara e a doutora Kelly Saito por contribuírem na etapa final desse estudo e pelas discussões científicas.

Ao Doutor Murilo Vieira Geraldo pela ajuda nos experimentos, interpretação de resultados, discussões científicas e especialmente pela amizade.

Aos Doutores Marco Aurélio Kulcsar, Celso Ubirajara Friguglietti e Ricardo Borges pela colaboração na coleta e análise patológica das amostras de CPT.

Ao Doutor Gregory Riggins pelos seus ensinamentos.

Ao Doutor Gilson Soares Baia pela paciência, ajuda e amizade.

Ao Doutor Emer Suavinho Ferro pelos aconselhamentos e diálogos sempre construtivos.

Ao Doutor Wilton Darleans da Cunha por ser um exemplo de força de vontade e determinação.

Aos novos e antigos amigos do Departamento de Biologia Celular e do Desenvolvimento: Fio, Zeca, Ronaldinho, Uchida, Miguel, Eivor, Marcela, Érico, professora Marília, professor GG, Rodrigo, Emília, Dani, Renata, Michele, Luiz e Fábio Tavares.

As Doutoras Anita Lal e Diana Hayward pela cordial doação dos vetores utilizados nesse estudo. 
Ao Conselho Nacional de Desenvolvimento Científico e Tecnológico (processo: 142019/2007-0) pela bolsa no Brasil e a Coordenação de Aperfeiçoamento Pessoal de Nível Superior (processo: 5939-11-9) pela bolsa no exterior.

Aos novos membros da minha família, Ada, Claudio, Dani, Diego, Miguel, Sandra e Má, pelo carinho e respeito. 
$x^{n}+y^{n}=z^{n}$

Pierre de Fermat 


\section{RESUMO}

Yamashita AS. Ativação da via de sinalização Notch pelos oncogenes RET/PTC e BRAFT1799A no carcinoma papilífero de tiroide e sua influência na diferenciação e proliferação celular. [tese (Doutorado em Biologia Celular e Tecidual)]. São Paulo: Instituto de Ciências Biomédicas, Universidade de São Paulo; 2013.

Alterações genéticas nos genes $R E T, R A S$ e $B R A F$ resultam na ativação constitutiva da sinalização MAPK e estão presentes em aproximadamente $70 \%$ dos carcinomas papilífero de tiroide, a forma mais prevalente de câncer de tiroide. Múltiplas vias de sinalização podem atuar em conjunto com a via MAPK na oncogênese tiroidiana. Nesse estudo, testamos a hipótese que a via MAPK regula a sinalização Notch e que o crosstalk entre as vias de sinalizações são importantes na regulação da diferenciação e proliferação celular no câncer de tiroide. A ativação condicional dos oncogenes RET/PTC3 e BRAFT1799A em linhagem de célula folicular normal de tiroide aumentou a atividade da via de sinalização Notch. Por outro lado, o bloqueio farmacológico da sinalização MAPK reduziu a sinalização Notch na linhagem celular TPC-1 derivada de carcinoma papilífero de tiroide. Glândulas tiroide de animais transgênicos expressando BRAFT1799A e amostras de carcinoma papilífero de tiroide apresentaram elevados níveis de $\mathrm{NOTCH} 1$. A superexpressão de $\mathrm{NOTCH} 1$ em célula folicular normal de tiroide aumentou a expressão proteica de NIS. A inibição farmacológica e por RNA de interferência da sinalização Notch apresentou um efeito antiproliferativo em linhagem de CPT. Além disso, a combinação do inibidor farmacológico de Notch e MAPK diminuiu a proliferação de células de carcinoma papilífero de tiroide. Esses dados sugerem um importante papel da sinalização Notch na oncogênese do carcinoma papilífero de tiroide induzida pela sinalização MAPK e que a via Notch pode ser uma potencial terapia adjuvante no câncer de tiroide.

Palavras-chave: Glândula tireóide. Neoplasias da tireóide. Oncoproteínas. Transdução de sinal celular. 


\begin{abstract}
Yamashita AS. Notch signaling activation by RET/PTC and BRAFT1799A in papillary thyroid cancinoma and their influence in cell differentiation and proliferation. [Ph. D thesis (Cell and Tissue Biology)]. São Paulo: Instituto de Ciências Biomédicas, Universidade de São Paulo; 2013.

Genetic alterations in RET, RAS and BRAF result in constitutive activation of the MAPK signaling and are present in approximately $70 \%$ of papillary thyroid carcinomas, the most prevalent form of thyroid cancer. Multiple signaling pathways can act with MAPK pathway in thyroid oncogenesis. In this study, we tested the hypothesis that MAPK pathway control Notch signaling and that the crosstalk between these pathways plays an important role in thyroid cancer cell differentiation and proliferation. The conditional activation of RET/PTC3 and BRAFT1799A enhanced Notch signaling pathway in normal follicular thyroid cell. By contrast, pharmacological inhibition of MAPK reduced Notch signaling in TPC-1 cell line derived from papillary thyroid carcinoma. Transgenic mice expressing BRAFT1799A restrict in thyroid gland and human papillary thyroid carcinoma samples showed higher Notch1 expression. NOTCH1 overexpression in normal thyroid follicular cell increased NIS protein expression. Pharmacological inhibition and RNA interference of Notch signaling showed an anti-proliferative effect in papillary thyroid carcinoma cells. Furthermore, the combination of MAPK and Notch signaling inhibitors reduced papillary thyroid carcinoma proliferation. These data suggest an important role of Notch signaling in papillary thyroid carcinoma induced by MAPK-related oncogenes and that Notch signaling pathway could be a potential adjuvant therapy in thyroid cancer.
\end{abstract}

Keywords: Thyroid gland. Thyroid neoplasia. Oncoproteins. Cellular sinal transduction. 


\section{LISTA DE ILUSTRAÇÕES}

Figura 1 - Organização histológica de folículos tiroidianos.

Figura 2 - Representação esquemática da ativação do receptor tirosina quinase e da sinalização MAPK e PI3K/AKT/mTOR.

Figura 3 - Organização estrutural dos domínios proteicos do receptor NOTCH1. 28

Figura 4 - Representação esquemática da sinalização Notch. 30

Figura 5 - Modelo de expressão gênica condicionada a doxiciclina. 35

Figura 6 - A expressão do receptor Notch1 é regulada pelos oncogenes RET/PTC3 e BRAFT1799A em célula folicular tiroidiana.

Figura 7 - A expressão do receptor Notch1 é regulada pelos oncogenes RET/PTC3 e BRAFT1799A em célula folicular de tiroide.

Figura 8 - Os oncogenes RET/PTC3 e BRAFT1799A ativam a via canônica da sinalização Notch em célula folicular tiroidiana. 50

Figura 9 - A modulação da sinalização Notch pela inibição de MEK é específica na linhagem TPC-1.

Figura 10 - A expressão de Notch1 está elevada em camundongos transgênicos e no carcinoma papilífero de tiroide. 54

Figura 11 - A expressão proteica de NOTCH1 não está relacionada com os níveis proteicos de NIS no carcinoma papilífero de tiroide. 56

Figura 12 - Superexpressão do domínio intracelular de Notch1 não modula a proliferação de célula normal de tiroide - PCCL3.

Figura 13 - Inibição de gama secretase acumula NOTCH1 na membrana plasmática e diminui a expressão de HES1 na linhagem TPC-1 de carcinoma papilífero de tiroide.

Figura 14 - Inibição da sinalização Notch diminui a proliferação em células de carcinoma papilífero de tiroide. 60

Figura 15 - A inibição da sinalização Notch promove parada em G2/M e regula genes envolvidos no controle do ciclo celular.

Figura 16 - Bloqueio da sinalização Notch induz apoptose em células derivadas de carcinoma papilífero de tiroide. 
Figura 17 - Silenciamento gênico de NOTCH1 reduz a proliferação celular na

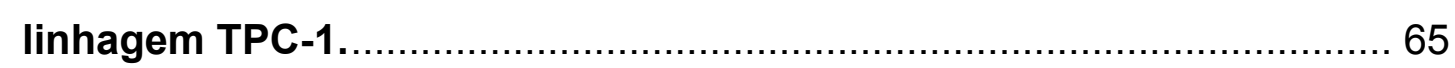

Figura 18 - Inibição da sinalização Notch aumenta o efeito antiproliferativo mediado pelo bloqueio da sinalização MAPK...................................... 66 


\section{LISTA DE TABELAS}

Tabela 1 - Principais características dos carcinomas de tiroide.......................... 25

Tabela 2 - Principais características das linhagens de células utilizadas nesse

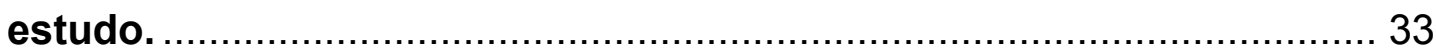

Tabela 3 - Oligonucleotídeos utilizados para análise da expressão gênica............ 41

Tabela 4 - Análise imunohistoquímica da expressão de NIS e NOTCH1 em amostras de carcinoma papilífero de tiroide. ........................................ 55 


\section{LISTA DE ABREVIATURAS E SIGLAS}

\begin{tabular}{|c|c|}
\hline Kb & kilobase \\
\hline kDa & kilodalton \\
\hline$\mu \mathrm{M}$ & micromolar \\
\hline $\mathrm{mM}$ & milimolar \\
\hline $\mathrm{nm}$ & nanomolar \\
\hline$\mu g$ & micrograma \\
\hline BRAF & do inglês, v-raf murine sarcoma viral oncogene homolog B1 \\
\hline CBF1 & do inglês, c-promoter biding factor 1 \\
\hline cDNA & DNA complementar \\
\hline Ct & do inglês, cycle threshold \\
\hline DMEM & do inglês, Dulbecco's Modified Eagle's Medium \\
\hline DMSO & dimetilsulfóxido \\
\hline DNA & ácido deoxirribonucléico \\
\hline DNase & deoxirribonuclease \\
\hline Dox & doxiciclina \\
\hline dNTP & deoxinucleotídeo trifosfato \\
\hline EGF & do inglês, Epidermal Growth Factor \\
\hline ERK & do inglês, Extracellular signal-Regulated Kinase \\
\hline GSI & do inglês, Gamma-secretase inhibitor \\
\hline MAPK & do inglês, Mitogen-Activated Protein Kinase \\
\hline
\end{tabular}




$\begin{array}{ll}\text { mRNA } & \text { RNA mensageiro } \\ \text { MTT } & \text { brometo de 3-(4,5-dimetil-2-tiazolil )-2,5-difenil-2H-tetrazólio } \\ \text { NIS } & \text { do inglês, sodium-iodide symporter } \\ \text { PAGE } & \text { do inglês, polyacrylamide gel electrophoresis } \\ \text { PBS } & \text { do inglês, phosphate buffered saline } \\ \text { PCR } & \text { do inglês, polimerase chain reaction } \\ \text { RAS } & \text { do inglês, } \text { Rat sarcoma } \\ \text { RET } & \text { do inglês, } \text { Rearrangement during transfection } \\ \text { RET/PTC } & \text { do inglês, } \text { Rearranged in Transformation/Papillary Thyroid Carcinomas } \\ \text { RNA } & \text { ácido ribonucléico } \\ \text { RNase } & \text { ribonuclease } \\ \text { RPMI } & \text { do inglês, Roswell Park Memorial Institute } \\ \text { RT } & \text { do inglês, reverse transcription } \\ \text { SDS } & \text { do inglês, sodium dodecyl sulfate } \\ \text { SiRNA } & \text { do inglês, small interfering RNA } \\ \text { TSH } & \text { do inglês, thyroid-stimulating hormone }\end{array}$




\section{SUMÁRIO}

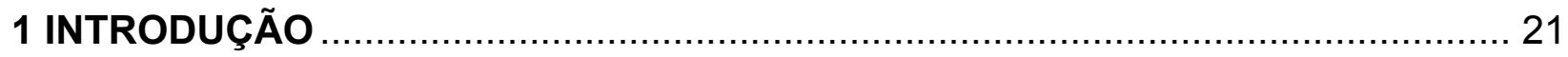

1.1 Alterações genéticas e das vias de sinalização no carcinoma papilífero de

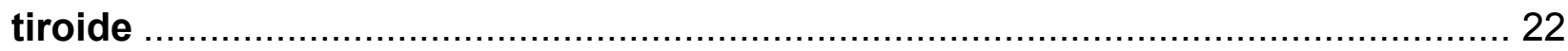

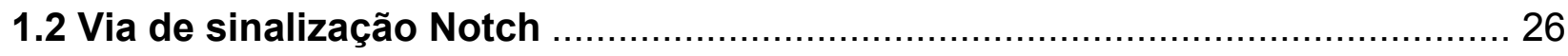

1.3 Via de sinalização Notch e câncer ................................................................... 30

2 OBJETIVOS

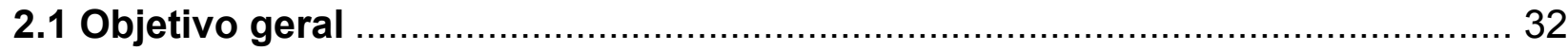

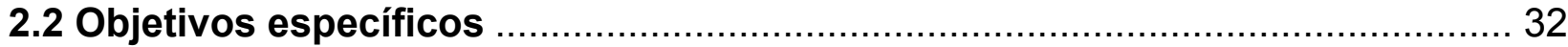

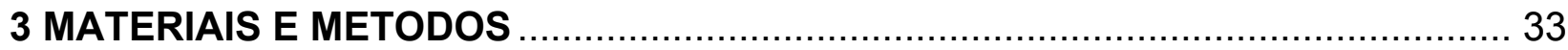

3.1 Linhagens celular e cultura de células ….................................................... 33

3.2 Indução dos oncogenes RET/PTC3 e BRAFT1799A ................................... 34

3.3 Tratamento com inibidores de MEK e inibidor de gama secretase .................. 36

3.4 Silenciamento gênico transiente de NOTCH1 na linhagem TPC-1 ................... 36

3.5 Estabelecimento de células isogênicas PCCL3 com expressão de NOTCH1 .. 37



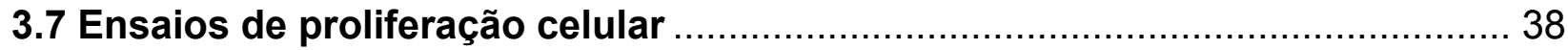

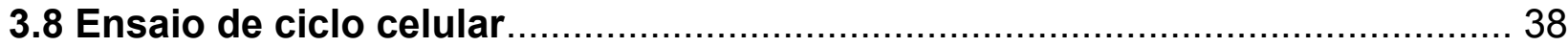

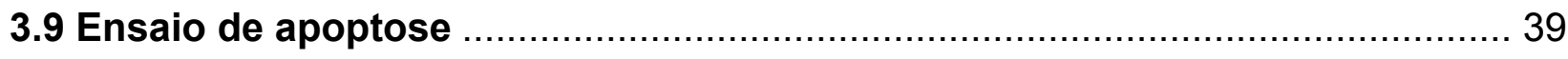

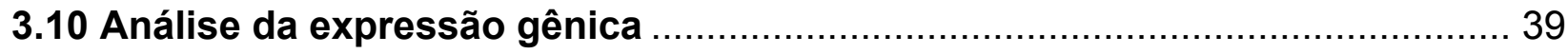

3.11 Análise da expressão proteica - Western blotting …................................. 42

3.12 Análise da expressão proteica - Imunohistoquímica ................................... 43

3.13 Análise de localização proteica - Imunofluorescência ................................. 44

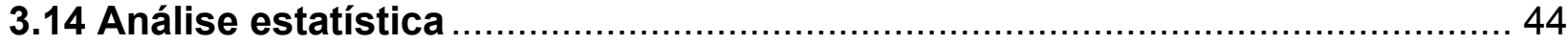

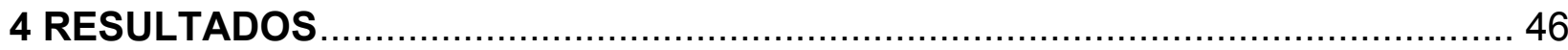

4.1 Influência da ativação dos oncogenes da via de sinalização MAPK sobre a

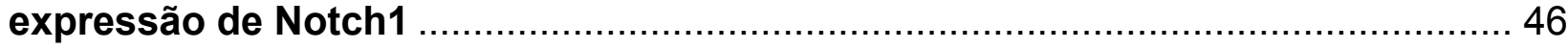

4.2 Avaliação funcional da via de sinalização Notch na ativação oncogênica da via MAPK

4.3 Efeito da inibição da via de sinalização MAPK sobre a expressão de NOTCH1 em células derivadas de carcinoma papilífero de tiroide 
4.4 Expressão de NOTCH1 em amostras de carcinoma papilífero de tiroide ........ 53 4.5 Regulação da diferenciação celular por Notch1 ......................................... 55 4.6 Sinalização Notch e seu papel na regulação da proliferação de célula folicular tiroidiana 56

4.7 Efeito da inibição da sinalização Notch na proliferação celular de células derivadas de carcinoma papilífero de tiroide ...................................................... 58

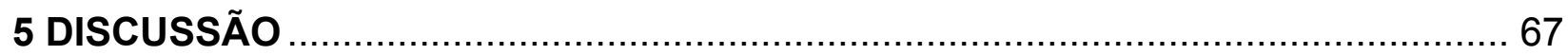

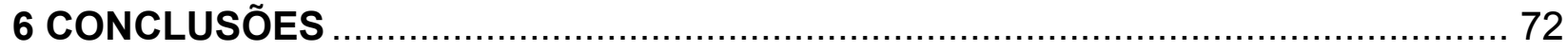

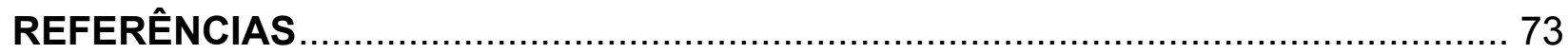




\section{INTRODUÇÃO}

A glândula tiroide é composta por dois lobos conectados por um istmo e localizase na traqueia anterior próximo a cartilagem cricóide. A glândula tiroide é constituída de dois tipos de células produtoras de hormônios, a célula folicular tiroidiana ou tirócito, produtora dos hormônios triiodotironina (T3) e tiroxina (T4); e a célula parafolicular ou célula $\mathrm{C}$, produtora do hormônio calcitonina. A célula folicular tiroidiana organiza-se em uma única camada de células cúbicas, formando folículos preenchidos por coloide (Figura 1). A proliferação da célula folicular tiroidina é controlada por diversos fatores, tais como o TSH e o iodo, e em condições basais apresenta uma baixa taxa de proliferação. No entanto, a alta incidência de nódulos palpáveis tiroidianos na população indica que a célula folicular tiroidiana pode apresentar um elevado potencial proliferativo (1).

\section{Figura 1 - Organização histológica de folículos tiroidianos.}

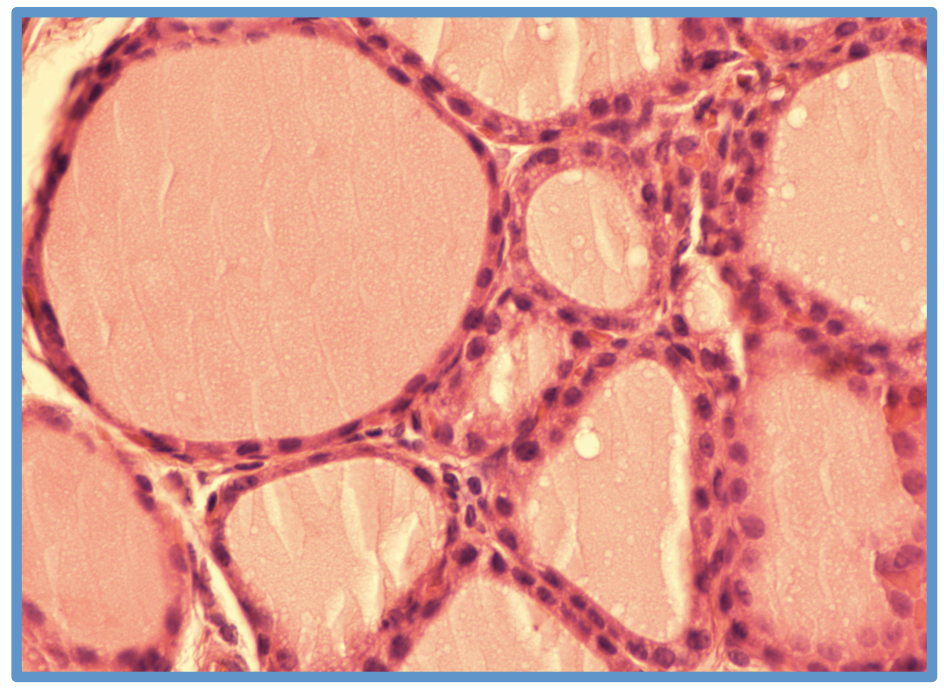

A célula folicular tiroidiana organiza-se formando pequenas esferas, denominadas folículos. Imagem representativa de folículos tiroidianos corados com Hematoxilina \& Eosina. Aumento: 400x. 
A grande maioria dos tumores da glândula tiroide se origina da célula folicular tiroidiana e somente $3-5 \%$ são originarias da célula parafolicular. As neoplasias malignas da glândula tiroide, derivadas da célula folicular, podem ser divididas de acordo com suas características histológicas em (a) carcinoma papilífero de tiroide, (b) carcinoma folicular de tiroide e (c) carcinoma anaplásico de tiroide (2). Na última década, a incidência do câncer de tiroide apresentou um crescimento contínuo $(3,4)$. Nos Estados Unidos, foram estimados aproximadamente 56.000 casos de câncer de tiroide no ano de 2012, levando a óbito aproximadamente 1.700 pessoas. No Brasil, foram estimados aproximadamente 10.600 casos de câncer de tiroide para o ano de 2012 (5).

O carcinoma papilífero de tiroide é o tipo de carcinoma mais frequente na glândula tiroide com prevalência em aproximadamente $80 \%$ dos casos de câncer de tiroide (6). A maioria dos pacientes com carcinoma papilífero de tiroide podem ser tratados com tiroidectomia, radioiodoterapia e supressão de TSH, com sobrevida maior que 20 anos em aproximadamente $90 \%$ dos casos (7). No entanto, aproximadamente 2-5\% dos pacientes com carcinoma papilífero de tiroide são refratários a radioiodoterapia e/ou apresentam metástases, resultando em um prognóstico desfavorável com sobrevida maior que 10 anos em somente $15 \%$ dos casos, sugerindo que novas alternativas terapêuticas são necessárias nos casos mais agressivos (8).

\subsection{Alterações genéticas e das vias de sinalização no carcinoma papilífero de tiroide}

Alterações genéticas podem ser classificadas funcionalmente em três tipos: (i) oncogenes; (ii) genes supressores tumorais; e (iii) genes envolvidos com estabilidade genética (9). Oncogenes e genes supressores tumorais participam diretamente na tumorigênese, regulando a proliferação celular pelo estímulo da divisão ou inibição da morte celular. Genes envolvidos com a estabilidade genética participam indiretamente no processo de proliferação celular facilitando o acúmulo de mutações (9).

No câncer de tiroide, alterações genéticas em receptores tirosina quinase e em efetores de vias de sinalização intracelular estão frequentemente alterados (Tabela 1). 
Receptores tirosina quinase são proteínas transmembrana com um domínio extracelular para ligação do ligante e um domínio catalítico intracelular. $\mathrm{Na}$ ausência do ligante, o receptor está desfosforilado e monomérico. Em contraste, na presença do ligante, o receptor se dimeriza e permite a ligação covalente de fosfatos em resíduos de tirosina no domínio catalítico da proteína, regulando sua atividade enzimática (10). A alteração conformacional do receptor gera sítios de ligação para proteínas sinalizadoras e proteínas adaptadoras na membrana plasmática, que por sua vez, ativam múltiplas vias de sinalização (10) (Figura 2). No genoma humano estão presentes 90 genes que codificam proteínas do tipo tirosina quinase, 58 genes são receptores tirosina quinase, distribuídos em 20 famílias de receptores de acordo com a sequência do domínio quinase (11). No câncer, mais de $50 \%$ dos receptores tirosina quinase estão funcionalmente alterados (12).

Em particular no carcinoma papilífero de tiroide, o rearranjo cromossômico do domínio tirosina quinase do receptor RET com a porção 5' de um gene heterólogo resulta na expressão de uma proteína quimérica RET/PTC (do inglês, Rearranged in Transformation/Papillary Thyroid Carcinomas) com ativação independente do ligante. Várias formas de rearranjo cromossômico foram identificadas de acordo com o gene envolvido, sendo o RET/PTC1 e o RET/PTC3 os mais frequentes no carcinoma papilífero de tiroide, em que o gene RET está fusionado com CCDC6 (também denominado H4) e NCOA4 (também denominado ELE ou RFG), respectivamente (1315). Mutações somáticas e germinativas no gene RET (do inglês, REarrangement during Transfection) são frequentes no carcinoma medular de tiroide, resultando na ativação constitutiva do domínio quinase do receptor independente da ligação do fator de crescimento $(16,17)$. 
Figura 2 - Representação esquemática da ativação do receptor tirosina quinase e da sinalização MAPK e PI3K/AKT/mTOR.

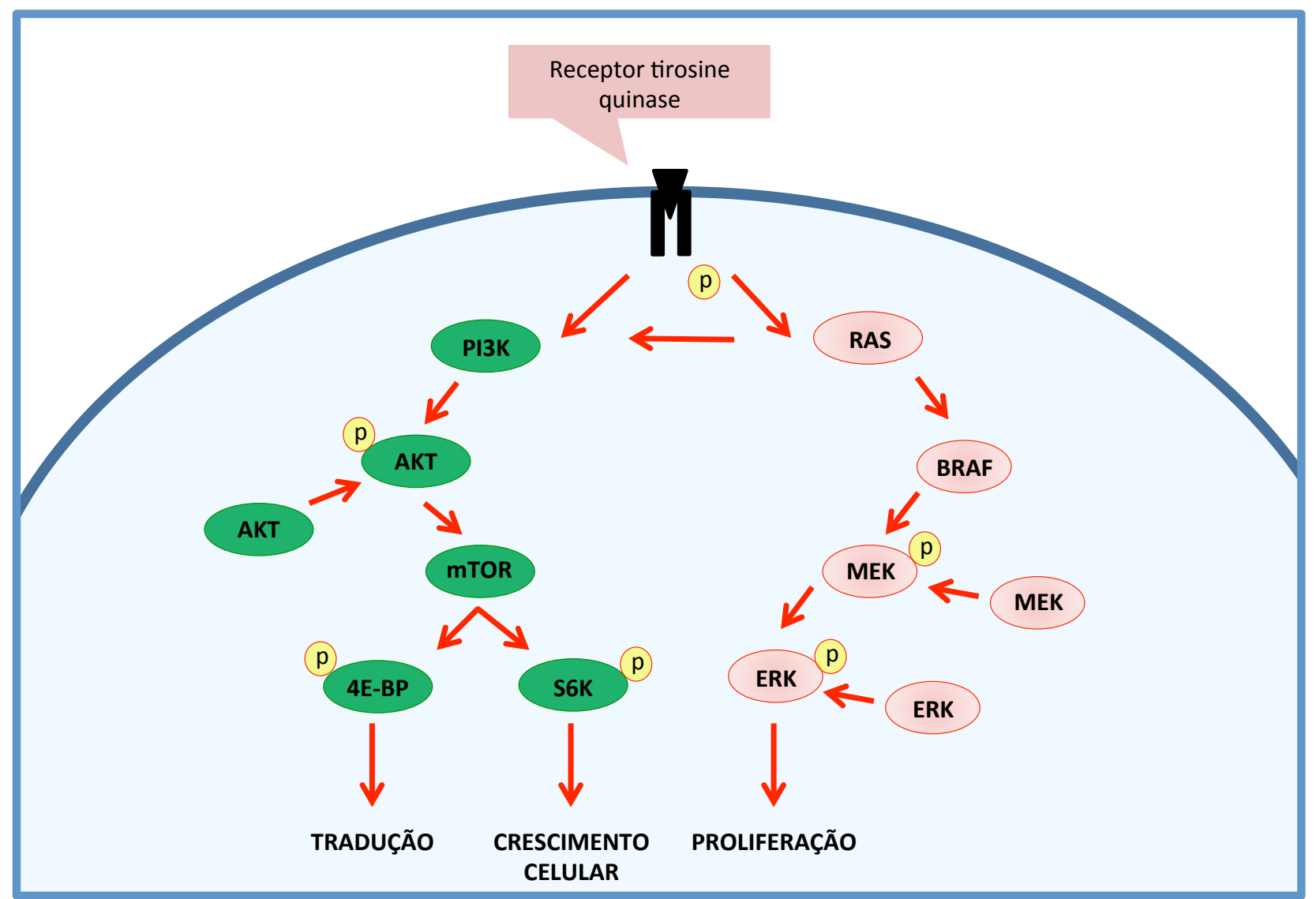

A ligação de fatores de crescimento em uma das subunidades do receptor tirosina quinase promove a dimerização e fosforilação do receptor. As vias de sinalizações RAS/MAPK e PI3K/AKT/mTOR são exemplos de sinalizações que podem ser ativadas por receptores do tirosina quinase e possuem um importante papel na patogênese do câncer de tiroide, regulando a tradução de RNAs mensageiros, o crescimento da célula e a proliferação celular. Em resumo, após a ativação do receptor, proteínas adaptadoras participam da transdução de sinal e promovem a fosforilação sequencial de MEK e ERK componentes da via de sinalização MAPK e da via de sinalização PI3K/AKT/mTOR, que por sua vez, amplificam o sinal gerado pelo ligante resultando no efeito biológico na célula.

Os receptores tirosina quinase propagam o sinal por meio da ativação de vias de sinalizações intracelular. A via de sinalização MAPK (do inglês, Mitogen-Activated Protein Kinase) apresenta importante papel na patogênese do câncer de tiroide. A sinalização MAPK integra o sinal obtido de receptores de superfície até o núcleo, transmitindo o sinal extracelular até o interior da célula. Devido sua grande importância biológica na regulação de diversos processos celulares, alterações genéticas em efetores da via de sinalização MAPK estão relacionadas diretamente com a 
oncogênese. Mutações que ativam RAS (do inglês, Rat sarcoma), particularmente HRAS e NRAS, são observadas principalmente em carcinoma folicular da tiroide e são menos frequentes no carcinoma papilífero de tiroide $(18,19)$. A mutação do gene $B R A F$ (do inglês, v-raf murine sarcoma viral oncogene homolog B1) é a alteração genética mais prevalente no carcinoma papilífero de tiroide, a mutação ocorre por meio da troca de uma timidina por uma adenina no nucleotídeo 1799 (T1799A) no éxon 15, resultando na substituição de uma valina por um ácido glutâmico (V600E) (20-22). A inserção de um resíduo de aminoácido de carga negativa adjacente ao sítio de fosforização resulta na ativação constitutiva do domínio quinase da proteína BRAF que fosforila componentes da via de sinalização MAPK (23).

Tabela 1 - Principais características dos carcinomas de tiroide.

\begin{tabular}{|c|c|c|c|c|}
\hline Características & $\begin{array}{l}\text { Carcinoma } \\
\text { papilifero }\end{array}$ & $\begin{array}{l}\text { Carcinoma } \\
\text { folicular }\end{array}$ & $\begin{array}{l}\text { Carcinoma } \\
\text { anaplásico }\end{array}$ & $\begin{array}{l}\text { Carcinoma } \\
\text { medular }\end{array}$ \\
\hline Tipo de célula & Folicular & Folicular & Folicular & Parafolicular \\
\hline Prevalência (\%) & $80-85$ & $10-15$ & $1-2$ & $3-5$ \\
\hline $\begin{array}{l}\text { Alteração genética } \\
\text { (frequência\%) }\end{array}$ & $\begin{array}{l}\text { BRAF }(40-50) \\
\text { RAS }(10-20) \\
\text { RET/PTC }(10-20) \\
T R K(<5)\end{array}$ & $\begin{array}{l}\text { RAS }(40-50) \\
\text { PAX8/PPARY (30-35) } \\
\text { PI3KCA }(<10) \\
\text { PTEN }(<10)\end{array}$ & $\begin{array}{l}\text { TP53 }(50-80) \\
\text { CTNNB1 (5-60) } \\
\text { RAS }(20-40) \\
\text { BRAF }(20-44) \\
\text { PI3KCA (10-20) } \\
\text { PTEN (5-15) } \\
\text { AKT1 }(5-10) \\
\text { APC (9) } \\
\text { AXIN (82) }\end{array}$ & $\begin{array}{l}R E T(>95)^{*} \\
R E T(40-50) \\
R A S(25)\end{array}$ \\
\hline
\end{tabular}

Nota: * frequência presente no carcinoma medular familiar.

Fonte: Adaptada de Ricarte-Filho et al. (2009); Smallridge et al. (2009); Nikiforav e Nikiforova (2011).

A via de sinalização PI3K/AKT/mTOR (do inglês, mammalian Target of Rapamycin) também é ativada pelos receptores tirosina quinase e participam do processo de tumorigênese tiroidiana. A sinalização inicia-se pela ativação da subunidade catalítica de PI3K, que resulta no recrutamento citoplasmático da proteína AKT, que fosforila diversas proteínas intracelulares. O complexo proteico mTOR é um alvo de AKT e atua, por meio de seus efetores, em etapas essenciais da divisão celular, induzindo a tradução de RNAs mensageiros e aumentando o crescimento da célula (Figura 2). Alterações genéticas no gene PI3KCA (do inglês, Phosphatidyllnositol-4,5- 


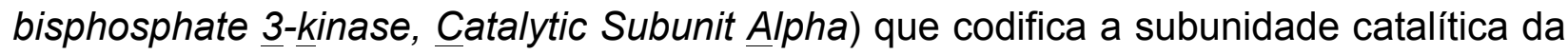
proteina PI3K e mutações em AKT1 (G49A) foram recentemente descritas e são frequentemente observadas no carcinoma anaplásico de tiroide $(24,25)$. Interessante notar que, alterações genéticas nesses genes co-existem com a mutação BRAFT1799A no carcinoma anaplásico de tiroide (24). Embora alterações genéticas em MTOR sejam relativamente raras no câncer, a via de sinalização mTOR está constitutivamente ativada principalmente em carcinoma papilifero de tiroide com mutação BRAFT1799A, sugerindo que essa via de sinalização possa atuar em conjunto com a via MAPK no câncer de tiroide (26).

As vias de sinalização intracelulares possibilitam um grande repertório de interações, fortalecendo o conceito de que a sinalização intracelular é realizada por uma plataforma, que possui como componentes um grande número de proteínas integradoras desses sinais. Nesse contexto, destacam-se as sinalizações que possuem importante papel na regulação de processos chave da homeostase celular e que podem atuar sinergicamente com a atividade da via MAPK na oncogênese tiroidiana.

\subsection{Via de sinalização Notch}

Os genes da família NOTCH são altamente conservados entre diferentes espécies e participam de um amplo espectro de processos fisiológicos, regulando proliferação, sobrevivência, diferenciação e apoptose em diferentes tecidos (27). Em 1917, Thomas Morgan demonstrou entalhes nas bordas das asas de Drosophila

melanogaster quando estudava os mecanismos hereditários Mendelianos, esse fenótipo foi denominado Notch (28). Essa curiosa característica fenotípica foi atribuída a haploinsuficiência de um gene, que posteriormente foi denominado como o gene Notch. Na década de 80, o gene Notch de Drosophila melanogaster foi clonado pelo grupo de pesquisa do professor Artavanis-Tsakonas (29). Em mamíferos estão descritos quatro receptores Notch (NOTCH1 - NOTCH4). O gene NOTCH1 é o mais conhecido da família, com locus gênico na região 9q34.3, o transcrito gera uma proteína transmembrana de 2555 aminoácidos com mais de $300 \mathrm{KDa}(30,31)$. Embora o transcrito seja traduzido em uma única cadeia polipeptídica, NOTCH1 sofre uma 
clivagem proteolítica no sítio S1 antes de ser transportado para membrana plasmática, caracterizando-se como um receptor heterodimérico (31). A proteína NOTCH1 possui um domínio extracelular com 36 repetições do tipo EGF e diversos sítios para adição de frutose e glicose, que auxiliam o dobramento adequado da proteína durante seu processamento no complexo de Golgi. Adjacente as repetições do tipo EGF na porção extracelular do receptor localiza-se o domínio com 3 repetições Notch-Lin12, importantes para inibição da ativação do receptor independente do ligante. Na porção intracelular do receptor NOTCH1 está presente o módulo de associação ao CBF1, importante para a ativação da via de sinalização. As repetições ankyrin permitem a formação do complexo ternário com outras proteínas permitindo o início da transcrição de genes alvos da via de sinalização Notch. Na porção C-terminal do receptor está presente o conservado domínio rico em prolina/ácido glutâmico/serina/treonina, com papel regulatório na estabilidade da proteína $(30,31)$ (Figura 3). 
Figura 3 - Organização estrutural dos domínios proteicos do receptor NOTCH1.

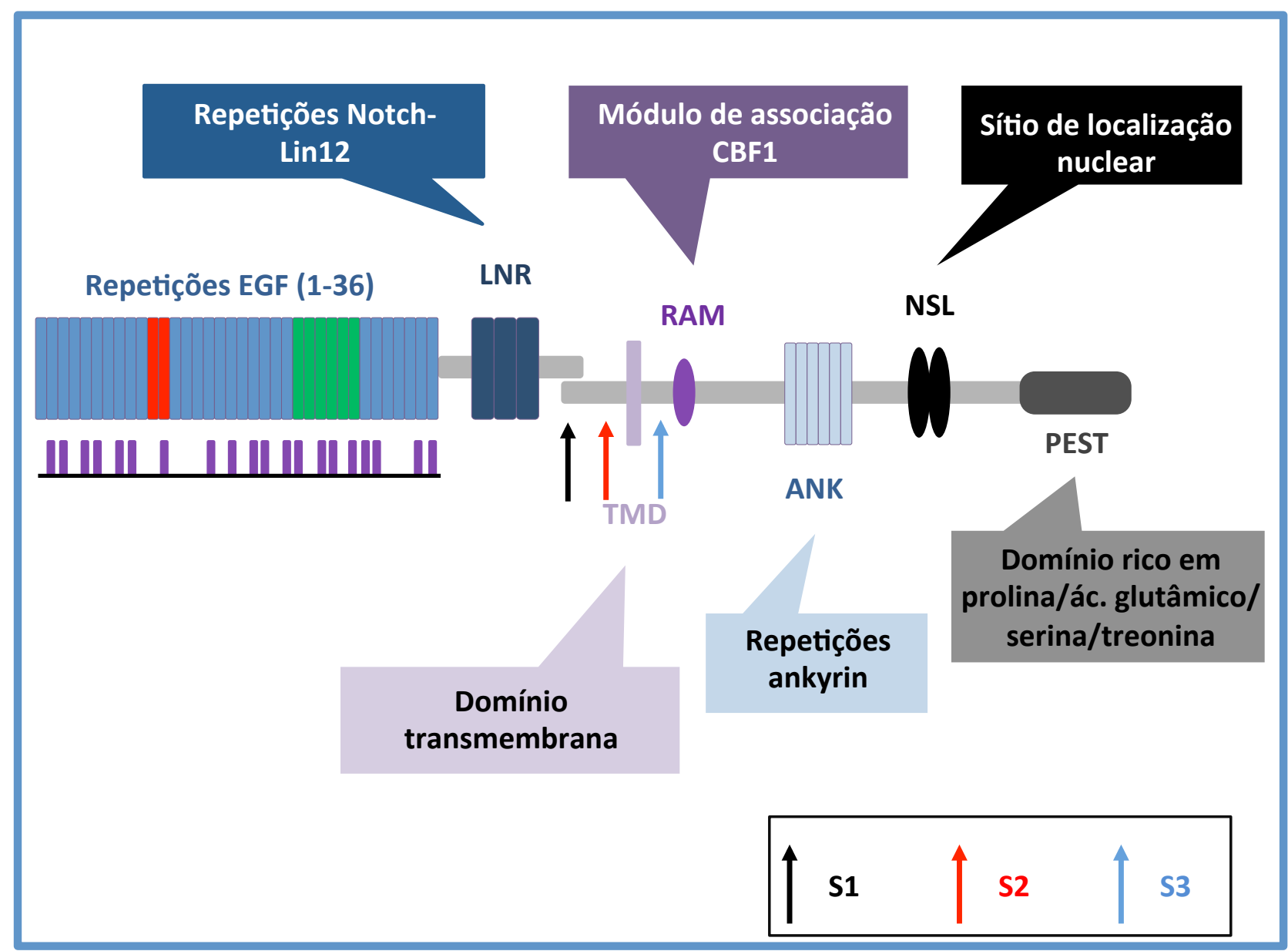

Esquema representativo dos domínios do receptor NOTCH1. A porção extracelular apresenta 36 repetições do tipo EGF e múltiplos sítios de glicosilação/fucosilação (representados na cor roxa). Ofut: Ofucosil transferase; LNR: Repetições Notch-Lin12; TMD: domínio transmembrana; RAM: núcleo de associação CBF1; ANK: repetições ankyrin; NSL: sítio de localização nuclear; e PEST: domínio rico em prolina / ácido glutâmico / serina / treonina. S1, S2 e S3 indicam os sítios de clivagens proteolíticas do receptor NOTCH1.

Os ligantes dos receptores Notch, Delta-Like (DLL1, DLL3 e DLL4) e Jagged (JAG1 e JAG2) são coletivamente chamados de proteínas DSL e localizam-se na membrana plasmática das células adjacentes, tornando necessário o contato célulacélula para o início da ativação da via de sinalização. Após a ligação com seu ligante, o receptor Notch altera sua conformação estrutural, expondo o sítio de clivagem S2 na porção extracelular do receptor para clivagem proteolítica, via ação da metaloproteinase TACE (do inglês, Tumour necrosis factor- $\underline{-}$-converting enzyme), a porção extracelular 
do receptor Notch é endocitado pela célula adjacente e direcionada para degradação proteica. O receptor Notch sofre uma segunda clivagem no sítio S3 do receptor na porção intracelular pelo complexo enzimático gama-secretase, que inclui as proteínas presinilin, niscatrin, Pen2 e APH1, liberando no citoplasma o domínio intracelular de Notch (Figura 4). O complexo gama-secretase é alvo da classe de drogas denominados inibidores de gama-secretase (GSI, do inglês, Gamma-secretase inhibitor), a inibição da clivagem impede a liberação do domínio intracelular de Notch no citoplasma inibindo sua atividade biológica (32).

No citoplasma, o domínio intracelular de Notch é translocado para o núcleo por meio da proteína adaptador importina- $\alpha$ e atua como fator de transcrição ligando-se ao seu co-ativador CSL ( $\underline{C B F 1}$ em mamífero; $\underline{S} u(H)$ em Drosophila e Lag-1 em C. Elegans), ativando genes alvos, tal como HES1, HERP1 e HERP2, sendo que recentemente foram descritos sítios de ligação para CBF1 no promotor de CCND1 (3335). Além disso, outros co-reguladores, incluindo MASTERMIND, CBP/p300 e SMRT, estão envolvidos no controle transcricional dependente da sinalização Notch (Figura 4). HES1 foi o primeiro gene descrito como alvo da sinalização Notch, aproximadamente 30 minutos após a ativação dos receptores Notch ocorre um aumento da expressão de HES1, servindo como paradigma da atividade da via de sinalização Notch $(36,37)$. 
Figura 4 - Representação esquemática da sinalização Notch.

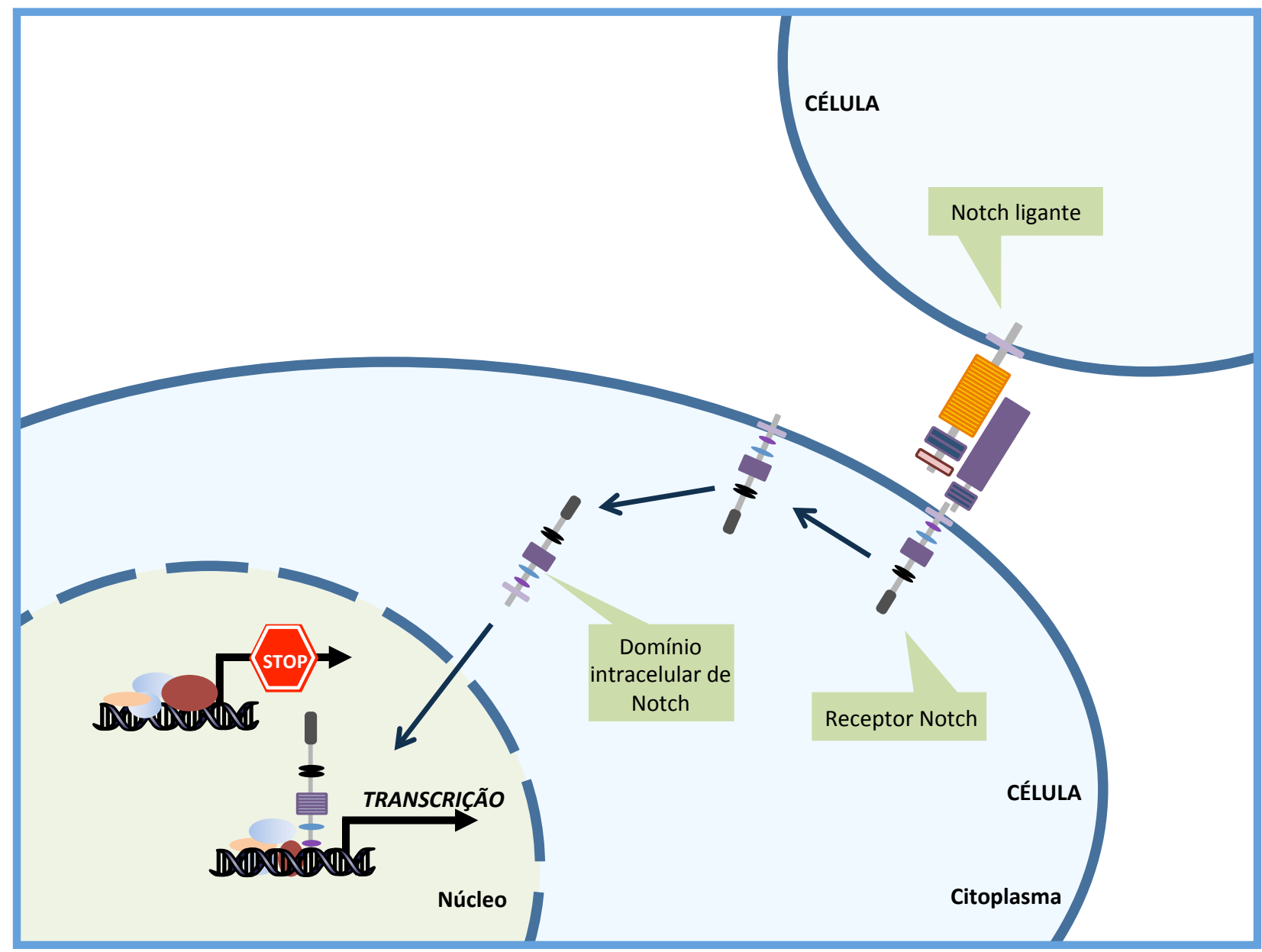

A ativação dos receptores $\mathrm{NOTCH}$ é realizada por meio da proteólise sequencial do receptor após a ligação de DELTA ou JAGGED, resultando na liberação do domínio intracelular de Notch, que é translocado para o núcleo. No núcleo, o domínio intracelular de Notch atua como fator de transcrição, ligando-se ao seu co-ativador CBF1, ativando a transcrição de genes alvos em conjunto com outros coreguladores.

\subsection{Via de sinalização Notch e câncer}

O papel da sinalização Notch no câncer foi originalmente demonstrado pela translocação cromossomal de NOTCH1 em pacientes com leucemia linfoblástica aguda de células $T$ (do inglês, $T$ cell acute lymphoblastic leukaemia) (38). Embora a translocação cromossômica seja rara em pacientes com leucemia linfoblástica aguda de células $T$, presente em aproximadamente $1 \%$ dos casos, mutações no domínio de heterodimerização do receptor e no domínio PEST, que resultam na clivagem 
proteolítica independente do ligante e no aumento da estabilidade do domínio intracelular de Notch, respectivamente, atinge aproximadamente $50 \%$ dos pacientes (39). O resultado é a ativação constitutiva da via Notch e da transformação maligna da célula (39). Devido sua participação em processos regulatórios em um grande número de tecidos, não é de se surpreender que alterações moleculares com ganho ou perda de função de componentes da sinalização Notch estejam envolvidas em diferentes tipos de câncer. De fato, no câncer de mama ocorre aumento da expressão de receptores Notch e sua ativação regula positivamente o crescimento independente de ancoragem, enquanto, a inibição da via de sinalização Notch reduz o crescimento de tumor em camundongos nude (40-42). Nosso grupo observou que a via de sinalização Notch, por meio da indução de seu gene alvo HES1, aumenta a instabilidade cromossomal e a aneuploidia em menigioma (43).

A participação da sinalização Notch no câncer de tiroide ainda é pouco conhecida. Ferretti et al. (2008) mostrou uma diminuição da expressão gênica dos receptores NOTCH1, NOTCH3 e HES1 no carcinoma anaplásico de tiroide (44). No carcinoma papilífero de tiroide o aumento da expressão proteica de $\mathrm{NOTCH} 1$ está associada a maior invasão linfonodal (45). Além disso, ensaios de expressão gênica em larga escala observaram elevados níveis de expressão dos ligantes dos receptores Notch, JAG1 e DLL3 $(46,47)$. Embora esses estudos forneçam informações acerca da importância dos receptores Notch, o papel funcional e sua regulação no câncer de tiroide continuam desconhecidos.

Estudos mostram uma interação da via MAPK com a sinalização Notch no câncer. A transformação maligna induzida por RAS em fibroblastos aumenta a expressão de $\mathrm{NOTCH} 1$, que por sua vez, regula a divisão celular e o crescimento independente de ancoragem $(48,49)$. Além disso, a interação da via de sinalização MAPK com a sinalização Notch participa de processos essenciais em neoplasias epiteliais, tais como, pâncreas, mama e pulmão (50-52). Nesse contexto, o entendimento da interação entre as vias de sinalizações MAPK e Notch merecem ser elucidados na oncogênese tiroidiana induzida por alterações genéticas em componentes da via de sinalização MAPK. 


\section{OBJETIVOS}

\subsection{Objetivo geral}

Avaliar a regulação da via de sinalização Notch na ativação dos oncogenes RET/PTC e BRAFT1799A e sua influência na diferenciação e proliferação celular no carcinoma papilífero de tiroide.

\subsection{Objetivos específicos}

1. Avaliar a via de sinalização Notch pelos oncogenes RET/PTC e BRAFT1799A; e

2. Avaliar o papel da sinalização Notch na diferenciação, divisão e apoptose em linhagem celular de carcinoma papilífero de tiroide. 


\section{MATERIAIS E METODOS}

\subsection{Linhagens celular e cultura de células}

As linhagens celulares TPC-1 de carcinoma papilifero de tiroide, PCCL3 de célula folicular de tiroide normal de rato e a linhagem PTC3-5 gerada a partir da linhagem PCCL3 foram gentilmente cedidas pelo Dr. James A. Fagin (Division of Endocrinology, Memorial Sloan-Kettering Cancer Center, NY, USA). A linhagem BCPAP de carcinoma papilífero de tiroide foi gentilmente cedidas pelo Dr. Massimo Santoro (Dipartimento di Biologia e Patologia Cellulare e Molecolare, University of Naples, Naples, Italy). As principais características das linhagens de células estão descritas na tabela 2.

Tabela 2 - Principais características das linhagens de células utilizadas nesse estudo.

\begin{tabular}{lccccc}
\hline $\begin{array}{l}\text { Linhagem } \\
\text { celular }\end{array}$ & Características & $\begin{array}{c}\text { Alterações } \\
\text { genéticas }\end{array}$ & $\begin{array}{c}\text { Linhagem } \\
\text { parental }\end{array}$ & Espécie & Referência \\
\hline PCCL3 & FT & - & - & rato & $(53)$ \\
\hline PC- $\varnothing$ & FT & vetor vazio & PCCL3 & rato & Presente estudo \\
\hline PC-NOTCH1 & FT & NOTCH1 & PCCL3 & rato & Presente estudo \\
\hline PC-rtTA & FT & rtTA & PCCL3 & rato & $(54)$ \\
\hline PC-BRAF & FT & $\begin{array}{c}\text { BRAFT1799A } \\
\text { induzível por } \\
\text { doxicilcina }\end{array}$ & PC-rTTA & rato & $(55)$ \\
\hline PTC3-5 & FT & $\begin{array}{c}\text { RET/PTC3 } \\
\text { induzível por } \\
\text { doxicilcina }\end{array}$ & PC-rTTA & rato & $(56)$ \\
\hline TPC-1 & CPT & $\begin{array}{c}\text { RET/PTC1 } \\
\text { (espontâneo) }\end{array}$ & - & humano & $(57)$ \\
\hline BCPAP & CPT & $\begin{array}{l}\text { BRAFT1799A } \\
\text { (espontâneo }\end{array}$ & - & humano & $(58)$ \\
\hline
\end{tabular}

Nota: FT: célula folicular de tiroide normal de rato; CPT: Carcinoma papilífero de tiroide. 
As linhagens TPC-1 e BCPAP foram cultivadas em meio Dubelcco's Modified Eagles Medium (DMEM) (Invitrogen Life Technology, Carlsbad, CA, U.S.A), suplementado com soro fetal bovino 5\% para TPC-1 e 10\% para BCPAP (Invitrogen Life Technology). A linhagem PCCL3 mantém em cultura a expressão dos marcadores típicos da diferenciação tiroideana, dependência de TSH para proliferação celular, síntese e secreção de tiroglobulina e habilidade de transportar iodo (53). A linhagem PCCL3, PTC3-5 e PC-BRAF foram cultivadas em meio Ham's F-12, suplementado com $1 \mathrm{mU} / \mathrm{mL}$ de TSH (Sigma, St Louis, MO, U.S.A.), $10 \mu \mathrm{g} / \mathrm{mL}$ de insulina (Sigma), $5 \mu \mathrm{g} / \mathrm{mL}$ de apotransferrina (Sigma), $10 \mathrm{ng} / \mathrm{mL}$ de hidrocortisona (Sigma), $100 \mathrm{U} / \mathrm{mL}$ de penicilina e $100 \mu \mathrm{g} / \mathrm{mL}$ de estreptomicina (Invitrogen Life Technology) e $1 \mu \mathrm{g} / \mathrm{mL}$ de anfotericina (Invitrogen Life Technology). As linhagens foram mantidas em incubadora sob condições de $95 \%$ de ar e $5 \%$ de $\mathrm{CO}_{2}$, a $37^{\circ} \mathrm{C}$.

\subsection{Indução dos oncogenes RET/PTC3 e BRAFT1799A}

A linhagem PTC3-5 e PC-BRAF são derivadas da linhagem PCCL3 e possuem a expressão do gene RET/PTC3 e BRAFT1799A, respectivamente, condicionados a doxiciclina (Calbiochem, San Diego, CA, U.S.A.). Para indução dos oncogenes nas linhagens PTC3-5 e PC-BRAF ultilizamos um sistema de expressão que consiste na expressão induzida por um derivado da tetraciclina, a doxiciclina (59). A linhagem PCCL3 foi transfectada com um vetor contendo o gene que codifica um mutante do repressor de tetraciclina (tetR) em fusão com gene que codifica o domínio ativador VP16, gerando uma linhagem celular denominada PC-rtTA. Os genes tetR e VP16 codificam um complexo proteico, denominado rtTA, que é capaz de reprimir a transcrição gênica na ausência de doxiciclina, mas ativa a transcrição do gene alvo na presença de doxiciclina. Os genes de interesse foram clonados no vetor pUHG10-3, sob efeito do elemento responsivo a tetraciclina (TRE) e um promotor mínimo de citomegalovirus ( $\left.P_{\operatorname{mincmv}}\right)$. Dessa forma, a doxiciclina liga-se ao complexo rtTA, promovendo a subsequente ligação ao TRE e a do gene de interesse (Figura 5). Para indução dos oncogenes, o meio de cultura contendo a concentração desejada de doxiciclina foi adicionado 24 horas após o semeamento das células. 
Figura 5 - Modelo de expressão gênica condicionada a doxiciclina.



(A) O elemento repressor (tetR) é transcrito em fusão ao domínio ativador VP16, formando o complexo denominado rtTA. (B) À medida que doxiciclina (Dox) é adicionada ao meio de cultura, este complexo em conjunto com a dox liga-se ao Elemento Responsivo a Tetraciclina (TRE) e ativa a transcrição do gene de interesse sob controle do promotor mínimo de citomegalovírus $\left(P_{\min C M v}\right)$. Modelo de expressão proteica do gene de interesse no sistema Tet-On em resposta ao aumento da concentração de dox. 


\subsection{Tratamento com inibidores de MEK e inibidor de gama secretase}

Para avaliar a influência da sinalização MAPK na via Notch, utilizamos os inibidores de MEK1 e MEK1/2, PD98059 (2'-Amino-3'-methoxyflavone) (20 $\mu \mathrm{M}$ ) e U0126 (10 $\mu \mathrm{M})$ (Promega, Madison, WI, U.S.A.) diluídos em DMSO. O papel da sinalização Notch em linhagens de tiroide foi analisado após o tratamento com o inibidor de gama secretase Z-Leu-Leu-Nle-CHO (GSI - do inglês, Gamma-secretase inhibitor) (Calbiochem, San Diego, CA, U.S.A.).

\subsection{Silenciamento gênico transiente de NOTCH1 na linhagem TPC-1}

RNA de interferência é uma importante ferramenta para análise funcional de genes. O siRNA (do inglês, small interfering RNA) realiza o silenciamento gênico póstranscricional utilizando seguimentos de $21 \mathrm{mer}$ com interação em regiões de um mesmo gene. Dessa forma, utilizando concentrações mais baixas de diferentes oligos se reduz o possível efeito off-target no silenciamento gênico. Os oligos utilizados para o silenciamento gênico de NOTCH1 foram obtidos comercialmente (siRNA Human NOTCH1, EHU150431 - Sigma) e testados em duas concentrações (10 e $30 \mathrm{nM}$ ) na linhagem TPC-1. O siRNA para silenciamento do gene EGFP (EHUEGFP - Sigma) foi utilizado como controle. Células TPC-1 foram semeadas na densidade de $1 \times 10^{5} \mathrm{em}$ placas de $60 \mathrm{~mm}$ para análise da expressão proteica e apoptose, para curva de crescimento foram semeadas $1 \times 10^{4}$ células por poço em placa de 6 poços. Após 24 horas, o meio de cultura Optimen (Invitrogen Life Technology) sem soro foi adicionado e mantido por 2 horas. Seguido da transfecção do siRNA e Lipofectamine 2000 (Invitrogen Life Technology) conforme as especificações do fabricante. 


\subsection{Estabelecimento de células isogênicas PCCL3 com expressão de NOTCH1}

Células PCCL3 foram semeadas na densidade de $1 \times 10^{5}$ células por poço em placas de 6 poços e $1 \mu \mathrm{g}$ do vetor pBABE-NOTCH1 ou pBABE vazio foi estavelmente transfectado utilizando Lipofectamine 2000 (Invitrogen Life Technology), gerando as linhagens $P C-N O T C H 1$ e $P C-\varnothing$, respectivamente. $O$ cDNA da região que codifica $O$ domínio intracelular do receptor NOTCH1 foi clonado nos sítios BamHI e EcoRI do vetor pBABE. A seleção foi realizada com $300 \mu \mathrm{g} / \mathrm{mL}$ de neomicina (Invitrogen Life Technology). Três populações da linhagem PC-NOTCH1 e duas populações da linhagem $P C-\varnothing$ foram selecionadas e após o ensaio de expressão proteica para detecção de NOTCH1 selecionamos a população PC-NOTCH1 com maior expressão de NOTCH1 para os ensaios posteriores. Os vetores pBABE-NOTCH1 e pBABE vazio foram gentilmente doados pela Dr. Anita Lal (University of California, San Francisco, CA, USA) (43).

\subsection{Ensaio de gene repórter}

A análise da atividade da via de sinalização Notch foi realizada na linhagem PCBRAF após a indução oncogênica de BRAFT1799A. Células PC-BRAF foram semeadas $1 \times 10^{4}$ células por poço em placa de 24 poços e co-transfectadas com $300 \mathrm{ng}$ do vetor 4xCBF1-Luc e $30 \mathrm{ng}$ do vetor pRL-CMV, 24 horas após a transfecção a indução do oncogene foi realizada com a adição de $1 \mu \mathrm{g} / \mathrm{mL}$ de doxiciclina no meio de cultura. Setenta e duas horas após a indução oncogênica, as células foram lavadas 2 vezes com PBS. A lise celular e a reação de luminescência foram realizadas utilizando o kit Dual-Glo Luciferase Assay (Promega, Fitchburg, WI, U.S.A.) conforme instruções do fabricante. A leitura do sinal de luminescência foi realizada em placa opaca de 96 poços, em luminômetro SpectraMax L (Molecular Devices, Sunnyvale, CA, USA). Os dados de luminescência obtidos da atividade da enzima luciferase foram normalizados pelos dados obtidos da atividade da renila. $\mathrm{O}$ vetor 4xCBF1-Luc foi gentilmente doado pela Dra. Diane S. Hayward (Johns Hopkins University, MD, USA) . 


\subsection{Ensaios de proliferação celular}

Contagem de células. Células TPC-1 e BCPAP foram semeadas na densidade de $1 \times 10^{4}$ células por poço em placa de 6 poços. Nos tempos determinados, as células foram submetidas à digestão enzimática contendo solução de tripsina a 0,5\% e EDTA a $0,02 \%$, fixadas em formaldeído $(3,7 \%)$ e mantidas a $4{ }^{\circ} \mathrm{C}$. O ensaio foi realizado em triplicata e o número total de células foi determinado utilizando citômetro de fluxo (Guava Technologies, Hayward, CA).

Ensaio de viabilidade celular - 3-(4,5-dimethylthiazolyl-2)-2,5-diphenyltetrazolium bromide (MTT). O MTT é um ensaio colorimétrico quantitativo baseado na clivagem do sal amarelo tetrazolium pela enzima mitocondrial desihidrogenase e subsequente formação de um cristal azul escuro insolúvel em água, que se acumula somente no interior das células viáveis. A absorbância detectada em espectrofotômetro é diretamente proporcional ao número de células viáveis (60). As células TPC-1 e BCPAP foram semeadas na densidade de $5 \times 10^{3}$ células por poço em placa de 96 poços. $O$ reagente MTT (Amresco, Solon, OH, U.S.A.) foi adicionado, seguido de incubação por 3 horas, solubilizado em uma solução de isopropanol/ HCL e a absorbância das amostras foi determinada em espectrofotômetro (Spectra Max Plus, Molecular Devices, Sunnyvale, EUA) no comprimento de onda de $595 \mathrm{~nm}$.

\subsection{Ensaio de ciclo celular}

Células TPC-1 e BCPAP foram semeadas na densidade de $1 \times 10^{5}$ células em placa de $60 \mathrm{~mm}$. Após o período de tratamento determinado, as células foram soltas das placas por meio de digestão enzimática com tripsina a 0,5\% e EDTA a 0,02\%, fixadas em álcool etílico $75 \%$ e mantidas a $4{ }^{\circ} \mathrm{C}$ por pelo menos 24 horas. Em seguida, as células foram lavadas em PBS e incubadas por 30 minutos com $100 \mu \mathrm{g} / \mathrm{mL}$ de RNase (Sigma) e por 1 hora com $50 \mu \mathrm{g} / \mathrm{mL}$ iodeto de propídeo (Sigma) em temperatura ambiente no escuro. O ensaio foi realizado em triplicata e o conteúdo de DNA foi analisado utilizando citômetro de fluxo (Guava Technologies - Millipore, Bilerica, MA, 
U.S.A.). O programa Guava Cytosoft foi utilizado para determinação do número de células nas diferentes fases do ciclo celular.

\subsection{Ensaio de apoptose}

A determinação do número relativo de células apoptóticas foi realizada por citometria de fluxo. As linhagens TPC-1 e BCPAP foram semeadas na densidade de $1 \times 10^{5}$ células em placas de $60 \mathrm{~mm}$, após o tratamento as células foram submetidas a digestão enzimática com tripsina e lavadas com PBS. A seguir, as células foram suspensas em solução contendo tampão de ensaio $1 \mathrm{X}$, solução de anexina-V FITC e solução de IP (Dead Cell Apoptosis Kit, Invitrogen Life Technology). O programa Guava Cytosoft foi utilizado para a análise dos dados. As células negativas para anexina- $V$ FITC e IP foram consideradas viáveis, as células positivas para anexina-V FITC foram consideradas células apoptóticas e as células positivas para IP e negativas para anexina-V FITC foram consideradas células necróticas.

\subsection{Análise da expressão gênica}

Extração do RNA total. O RNA total foi isolado das amostras usando reagente Trizol (Invitrogen Life Technology) seguindo recomendações do fabricante. A concentração do RNA total foi determinada medindo a absorbância de $260 \mathrm{~nm} / 280 \mathrm{~nm}$.

Reação de transcrição reversa $(R T)$. Foi utilizado $1 \mu \mathrm{g}$ de RNA total na reação contendo $500 \mu \mathrm{g} / \mathrm{mL}$ Oligo dt, $10 \mathrm{mM}$ de dNTP mix, 1x First-Strand Buffer, 0,1 M de DTT, $40 \mathrm{U}$ de RNaseOut e $200 \mathrm{U}$ de transcriptase reversa SuperScript II (Invitrogen Life Technology). A transcrição reversa foi realizada a $37^{\circ} \mathrm{C}$ por 50 minutos, seguido de um ciclo à $70^{\circ} \mathrm{C}$ por 15 minutos.

PCR em tempo real. Técnica usada para estimar a expressão relativa de RNA mensageiro nos genes testados, comparando as amostras e o controle interno RPL-19 (Ribosomal Protein L19) em duplicata, baseado na deteç̧ão em tempo real de produtos do PCR medidos por fluorescência, quantificado com o detector de sequência $A B I$ Prism 7300 (Applied Biosystems Life Technology). Os dados foram inicialmente 
expressos como um limiar de ciclagem ( $\mathrm{Ct}$; do inglês, cycle threshold) que representa uma linha de base de detecção de fluorescência, correspondente a fase exponencial. A expressão de cada gene alvo foi determinada utilizando-se a fórmula $2^{-\triangle \Delta C T}$ (61). $O 2^{-}$ $\triangle \triangle \mathrm{CT}$ para amostra controle é igual ao valor 1 e para as demais amostras os valores foram representados em número de vezes comparado à amostra controle, exceto nas amostras de carcinoma papilífero de tiroide humana em que utilizamos o programa $Q$ Gene (62). Para a reação de PCR foi utilizado condições de ciclagem prédeterminadas, sendo duas etapas de $50{ }^{\circ} \mathrm{C}$ por 2 minutos e $95{ }^{\circ} \mathrm{C}$ por 10 minutos, a amplificação ocorre em 40 ciclos: a desnaturação a $95{ }^{\circ} \mathrm{C}$ por 15 segundos e anelamento e extensão a $60{ }^{\circ} \mathrm{C}$ por 60 segundos. Os oligos utilizados no presente estudo estão descritos na tabela 3 e foram desenhados com base no banco de dados Genbank com o auxílio do programa Primer Express (Applied Biosystems Life Technolgy). 
Tabela 3 - Oligonucleotídeos utilizados para análise da expressão gênica.

\begin{tabular}{|c|c|c|c|}
\hline $\begin{array}{l}\text { Gene } \\
\text { (espécie) }\end{array}$ & Nome oficial & Sequência $\left(5^{\prime} \rightarrow 3^{\prime}\right)$ & Acesso \\
\hline NOTCH1 $(H)$ & Notch1 & $\begin{array}{l}\text { Fw: GCTAACAAAGATATGCAGAACAACA } \\
\text { Rev: GTCCCGGTTGGCAAAGTG }\end{array}$ & NM_017617 \\
\hline HES1 $(H)$ & Hairy and enhancer of split 1 & $\begin{array}{l}\text { Fw: AGGCGGACATTCTGGAAATG } \\
\text { Rev: AGCGCAGCCGTCATCTG }\end{array}$ & NM_005524 \\
\hline $\operatorname{CCND1}(H)$ & Cyclin D1 & $\begin{array}{l}\text { Fw: CTGTGCATCTACACCGACAACTC } \\
\text { Rev: CCAGGTTCCACTTGAGCTTGTT }\end{array}$ & NM_053056.2 \\
\hline$C D K N 1 A(H)$ & $\begin{array}{l}\text { Cyclin-dependent kinase } \\
\text { inhibitor } 1 A(p 21, \text { Cip1) }\end{array}$ & $\begin{array}{l}\text { Fw: CTGGAGACTCTCAGGGTCGAA } \\
\text { Rev: GGCGTTTGGAGTGGTAGAAATCT }\end{array}$ & NM_000389.4 \\
\hline$C D K N 1 B(H)$ & $\begin{array}{l}\text { Cyclin-dependent kinase } \\
\text { inhibitor } 1 B(p 27, \text { Kip1) } \\
\text { CDC28 protein kinase }\end{array}$ & $\begin{array}{l}\text { Fw: AGACGGGGTTAGCGGAGCAA } \\
\text { Rev: TCTTGGGCGTCTGCTCCACA }\end{array}$ & NM_004064.3 \\
\hline CKS2 $(H)$ & $\begin{array}{l}\text { regulatory } \\
\text { subunit } 2 \\
\text { Minichromosome }\end{array}$ & $\begin{array}{l}\text { Fw: GGCCCACAAGCAGATCTACTACTC } \\
\text { Rev: GGTAACATAACATGCCGGTACTC }\end{array}$ & NM_001827.1 \\
\hline MCM6 $(H)$ & $\begin{array}{l}\text { maintenance } \\
\text { complex component } 6\end{array}$ & $\begin{array}{l}\text { Fw: TGCCTGACGTCTCCAAGCTTA } \\
\text { Rev: CACTGACACGGGAATTAGTTTCTG }\end{array}$ & NM_005915.4 \\
\hline$M A D 2 L 1(H)$ & $\begin{array}{l}\text { MAD2 mitotic arrest deficient- } \\
\text { like } 1\end{array}$ & $\begin{array}{l}\text { Fw: CGTGGCCGAGTTCTTCTCA } \\
\text { Rev: AGATGGATATATGCCACGCTGAT }\end{array}$ & NM_002358.3 \\
\hline$R P L 19(H)$ & Ribosomal protein L19 & $\begin{array}{l}\text { Fw: TCTCATGGAACACATCCACAA } \\
\text { Rev: TGGTCAGCCAGGAGCTTCTT }\end{array}$ & NM_000981.3 \\
\hline $\operatorname{Notch} 1(R)$ & Notch 1 & $\begin{array}{l}\text { Fw: AGCCAACAAAGACATGCAGAAC } \\
\text { Rev: GTCCCGGTTGGCAAAGTG }\end{array}$ & NM_001105721 \\
\hline Hes1 (R) & Hairy and enhancer of split 1 & $\begin{array}{l}\text { Fw: GAAAACACTGATTTTGGATGCACTT } \\
\text { Rev: CGCGGTACTTCCCCAACAC }\end{array}$ & NM_024360 \\
\hline $\operatorname{Jag} 1(R)$ & Jagged 1 & $\begin{array}{l}\text { Fw: GCCATTTCTGCCGAAGACAT } \\
\text { Rev: GCTGTTCCCATCCCGTTTACT }\end{array}$ & NM_019147.1 \\
\hline$R p / 19$ (R) & Ribosomal protein L19 & $\begin{array}{l}\text { Fw: GGCCCGCAAGAAGCTACTG } \\
\text { Rev: TTCGTGCTTCCTTGGTCTTAGA }\end{array}$ & NM_031103.1 \\
\hline
\end{tabular}

Nota: Nomenclatura oficial para as espécies Rattus norvegicus $(R)$ e Homo sapiens $(H)$ de acordo com os bancos de dados RGD - Rat Genome Database (http://rgd.mcw.edu/) e HGNC - HUGO gene (http://www.genenames.org/), respectivamente. 


\subsection{Análise da expressão proteica - Western blotting}

Extração de proteínas. As células foram lisadas em tampão RIPA (Tris-HCl 10 $\mathrm{mM}, \mathrm{pH}$ 7.5; deoxicolato de sódio1\%; triton X-1001\%; $\mathrm{NaCl} 150 \mathrm{mM}$; SDS 0.1\%) na presença de inibidores de protease e fosfatase (Sigma). A concentração de proteína das amostras foi realizada pelo método de Bradford conforme a descrição do fabricante (Bio-Rad Laboratories, Hercules, CA, U.S.A.).

Separação das proteínas por SDS-PAGE. As proteínas foram desnaturadas a 95 ${ }^{\circ} \mathrm{C}$ por 5 minutos em tampão composto de uréia $8 \mathrm{M}$, Tris-HCl 62,5 mM, SDS $10 \%$ e $\beta$ mercaptoetanol $5 \%$. Após esse procedimento, o volume equivalente a $15-30 \mu \mathrm{g}$ de proteínas foi aplicado ao gel de poliacrilamida (4\% para retenção e $8-10 \%$ para separação das proteínas) e as proteínas foram separadas por eletroforese por cerca de aproximadamente 3 horas a $70 \mathrm{~V}$.

Transferência (Western blotting). As proteínas das amostras separadas por eletroforese foram transferidas para membrana de nitrocelulose. Para tanto, o gel foi colocado sobre uma membrana de nitrocelulose (Hybond ECL, Amersham Biosciences, Piscataway Township, NJ, U.S.A.), e imerso em cuba contendo tampão de transferência (Tris- $\mathrm{HCl}$ 0,25 M, pH 8.0; glicina 0,2 M e metanol 20\%) (63). Nestas condições, a voltagem foi regulada para $15 \mathrm{~V}$ overnight. Ao final da eletrotransferência, a membrana foi lavada em PBS, corada com Ponceau S, a fim de verificar a presença das proteínas e descorada com água destilada.

Bloqueio e incubação. As membranas foram incubadas por 1 hora com $5 \%$ de leite em pó desnatado em PBS-Twen 0,05\% para bloqueio dos sítios antigênicos inespecíficos. Decorrido este período, as membranas foram lavadas com PBS-Tween 0,05\% e incubadas sob agitação em solução de anticorpos IgG anti-Notch1 policlonal produzido em coelho (1:500; C20), IgG anti-p-ERK (tyr 214) monoclonal produzido em camundongo (1:1000; E4), IgG anti-ERK policlonal produzido em coelho (1:1000; K23), IgG anti- $\alpha$-Tubulina monoclonal produzido em camundongo (1:1000; B-7) (Santa Cruz Biotechnology, Santa Cruz, CA, U.S.A.), IgG anti-Ciclina D1 produzido em camundongo (1:1000; 556470) (BD Pharmigen, CA, U.S.A.), IgG anti-a-Actina policlonal produzido em coelho (1:1000; A2066) (Sigma) e IgG anti-NIS produzido em coelho (gentilmente 
doado pela Dra. Sissy Jhiang). Após este período, as membranas foram lavadas em PBS-Tween 0,05\% e incubadas por 2 horas na presença de anticorpo secundário (IgG anti-coelho conjugada a peroxidase ou IgG anti-camundongo conjugada a peroxidase) (Amersham Biosciences).

Revelação. O complexo proteína-anticorpo foi detectado após incubação da membrana com solução reveladora contendo $10 \mu \mathrm{M}$ de ácido pcumárico (Sigma), 50 $\mu \mathrm{M}$ de luminol, $2,5 \mu \mathrm{L} / \mathrm{mL}$ de $\mathrm{H}_{2} \mathrm{O}_{2}(3,6 \%)$ em Tris- $\mathrm{HCl}(100 \mathrm{mM}$; $\mathrm{pH} 8,8)$ por 1 minuto. A luminescência obtida após a incubação foi detecta em filme autoradiográfico Hyperfilm ECL® (GE Healthcare, Piscataway Township, NJ, U.S.A.).

\subsection{Análise da expressão proteica - Imunohistoquímica}

Camundongos transgênicos da linhagem FVB/N com expressão de BRAFT1779A na glândula tiroide foram gentilmente cedidas pelo Dr. James A. Fagin (Division of Endocrinology, Memorial Sloan-Kettering Cancer Center, NY, USA). promotor de tiroglobina bovino fusionado ao cDNA do gene humano BRAFT1799A contendo o sinal de poliadenilação foi injetado em óvulos fertilizados em camundongos FVB/N e implantado em camundongos fêmeas pseudográvidas. Esses camundongos apresentam ativação da via MAPK específica na glândula tiroide, perda de marcadores de diferenciação tiroidiana e características histológicas de carcinoma papilífero de tiroide (64). Amostras de tecido tiroidiano provenientes do banco de tecidos tiroidianos foram utilizados no presente estudo.

O ensaio de imunohistoquímica foi realizado em amostras de tecido humano ( $\mathrm{n}$ $=20$ ) e tecidos de camundongos ( $n=8$ por grupo) emblocadas em parafina. $O$ micro arranjo de tecidos foi estabelecido conforme descrito previamente somente nas amostras de tecido humano utilizando $1 \mathrm{~mm}$ de tecido por caso em duplicata $(65,66)$. 0 procedimento de imunohistoquímica foi realizado pelo método indireto de três etapas. Os tecidos foram cortados $(3 \mu \mathrm{m})$, desparafinizados, hidratados e o bloqueio da peroxidase endógena foi realizado com $\mathrm{H}_{2} \mathrm{O}_{2} 3 \%$. Os tecidos foram incubados com IgG anti-Notch1 policlonal produzido em coelho (1:100; C-20) (Santa Cruz Biotechnology) e IgG anti-NIS produzido em coelho (1:250) (cordialmente doado pela Dra. Sissy Jhiang) 
overnight, seguido da incubação por 2 horas com o anticorpo secundário biotinilado IgG anti-coelho (Amersham Biosciences). Após a incubação com biotina-estreptavidinaperoxidase, a reação foi revelada utilizando uma mistura de 3'3-diaminobenzidina com $\mathrm{H}_{2} \mathrm{O}_{2}$. Os cortes foram contracorados com hematoxilina de Gill. O controle negativo foi realizado na ausência do anticorpo primário. A presença de imunomarcação de cor marrom visíveis ao microscópio de luz (Eclipse E600 Nikon, Japan) indica a positividade. A intensidade da positividade da marcação nos tecidos foi avaliada e classificada como negativa, fraca, moderada e forte.

\subsection{Análise de localização proteica - Imunofluorescência}

Células TPC-1 foram semeadas na densidade de $3 \times 10^{4}$ células por poço sobre lamínulas de vidro em placas de 6 poços. Após o tratamento com GSI por 48 horas as células foram fixadas em paraformoldeído 3,7\% em PBS e permeabilizadas com Triton $\mathrm{X}-100 \quad 0,5 \%$. O bloqueio de sítios inespecíficos foi realizado com albumina bovina sérica $1 \%$ por 30 minutos. As lamínulas foram incubadas com IgG anti-Notch1 policlonal produzido em coelho (1:200; C-20) e IgG anti- $\alpha$-Tubulin monoclonal produzido em camundongo (1:500; B-7) (Santa Cruz Biotechnology) overnight a $4{ }^{\circ} \mathrm{C}$. Após as lavagens com PBS, as células foram incubadas com os anticorpos secundários lgG anti-coelho conjugada a Alexa Fluor 488 e anti-camundongo conjugada a Alexa Fluor 532 (1:500) (Invitrogen Life Technology) por duas horas a temperatura ambiente. Como controle negativo o anticorpo primário foi omitido. O núcleo foi marcado com 4',6diamidino-2-phenylindole DAPI (1 $\mu \mathrm{g} / \mathrm{ml}$, Sigma). Subsequentemente, as lamínulas foram montadas utilizando UltraCruz Mounting Medium (Santa Cruz Biotechnology) e analizadas em microscópio multifotônico Zeiss LSM 780 (Carl Zeiss, Jena, Germany).

\subsection{Análise estatística}

Os dados foram expressos como média \pm erro padrão da média, foi utilizado o test- $t$ de Student para comparação de duas médias. Quando necessário foi utilizado a análise de variância de duas via (ANOVA-two way), seguido do pós-teste de Bonferroni. 
O valor adotado para significância foi de $5 \%(p<0,05)$ e a análise estatística foi realizada no programa GraphPad Prism 5 (Prism, La Jolla, CA, USA). 


\section{RESULTADOS}

\subsection{Influência da ativação dos oncogenes da via de sinalização MAPK sobre a expressão de Notch1}

Para avaliar o possível mecanismo de interação entre a via de sinalização MAPK e Notch utilizamos duas linhagens de célula folicular tiroidiana normal de rato (PCCL3) com expressão dos genes RET/PTC3 e BRAFT1779A condicionados a doxiciclina (dox), denominadas PTC3-5 e PC-BRAF, respectivamente. A adição de concentrações crescentes de dox é capaz de induzir a expressão do gene de interesse de modo dose dependente. A ativação dos oncogenes RET/PTC3 e BRAFT1779A aumentou de modo dose dependente a expressão gênica de Notch1 (Figura 6A). Como indicador da atividade da via de sinalização MAPK ativada pelos oncogenes avaliamos a expressão proteica de ERK (do inglês, Extracellular signal-regulated kinase) fosforilada, que de forma similar à expressão protéica de Notch1 apresentou um padrão de aumento dose dependente (Figura 6B). 
Figura 6 - A expressão do receptor Notch1 é regulada pelos oncogenes RET/PTC3 e BRAFT1799A em célula folicular tiroidiana.

A
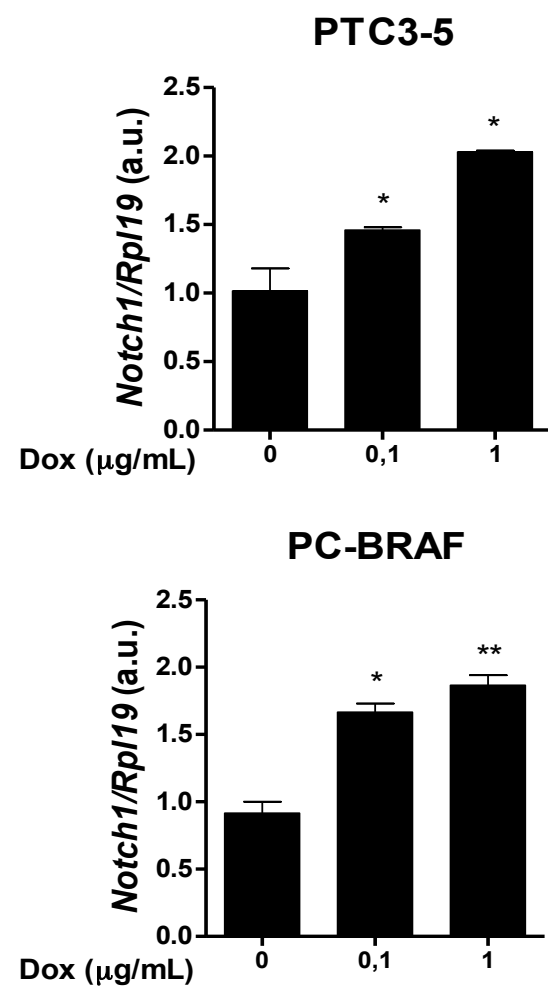

B

PTC3-5

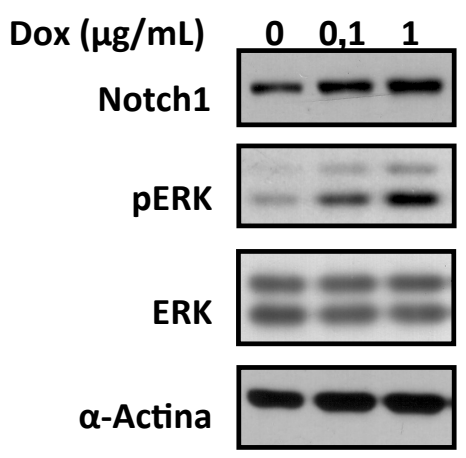

PC-BRAF
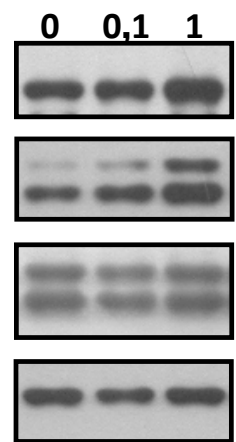

(A) As linhagens PTC3-5 e PC-BRAF foram tratadas com as concentrações indicadas de doxiciclina (Dox) por 72 horas e a análise da expressão gênica de Notch1 realizada por PCR em tempo real. Dados apresentados como média $\pm \operatorname{EP}(n=3)$. $\left(^{*}\right) p<0.05$ versus grupo Controle; $\left(^{* *}\right) p<0.01$ versus grupo Controle. u.a. unidades arbitrárias. (B) As linhagens PTC3-5 e PC-BRAF foram tratadas com doxiciclina por 72 horas e $30 \mu \mathrm{g}$ de proteínas foram separadas por SDS-PAGE e transferidas para uma membrana de nitrocelulose. A membrana foi incubada com anti-Notch1, anti-pERK, anti-ERK e anti-a-Actina.

A ativação do oncogene RET/PTC3 aumentou a expressão gênica de Notch1 após 24 horas e manteve-se elevada 72 horas após a ativação do oncogene. $\mathrm{Na}$ ativação do oncogene BRAFT1799A na linhagem PC-BRAF houve um aumento na expressão de Notch1 após 24 horas, com pico de expressão gênica em 48 horas após a indução do oncogene (Figura 7A). A análise da expressão proteica por Western blotting, demonstrou um aumento sustentado da fosforilação de ERK e um aumento da expressão proteica de Notch1 em ambas linhagens celulares analisadas após a ativação dos oncogenes (Figura 7B). 
Figura 7 - A expressão do receptor Notch1 é regulada pelos oncogenes RET/PTC3 e BRAFT1799A em célula folicular de tiroide.

A

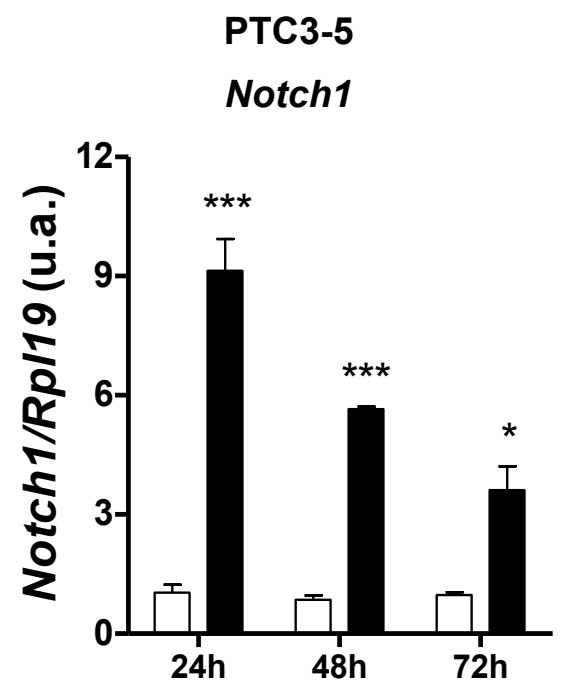

PC-BRAF

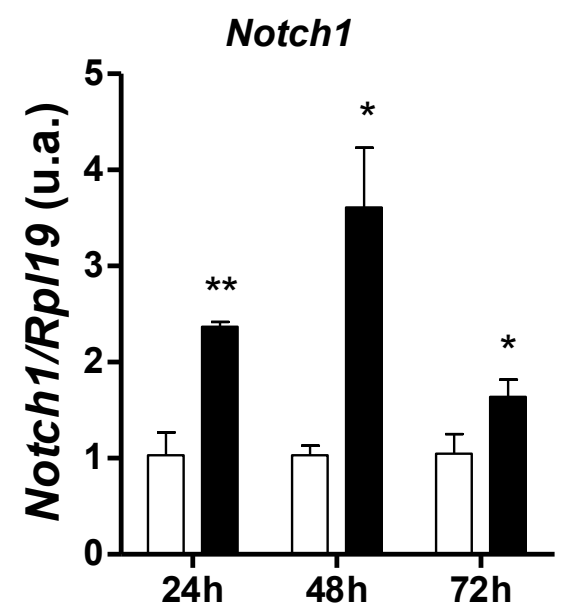

B

PTC3-5



PC-BRAF

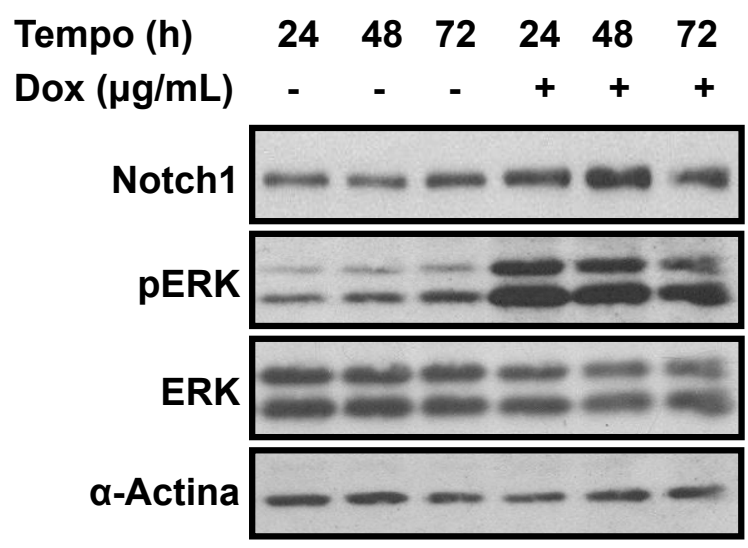

(A) As linhagens PTC3-5 e PC-BRAF foram tratadas com $1 \mu \mathrm{g} / \mathrm{mL}$ de doxiciclina (Dox) nos tempos indicados e a análise da expressão gênica de Notch1 foi determinada pela técnica de PCR em tempo real. Dados expressos como média $\pm \operatorname{EP}(n=3)$. $\left({ }^{*}\right) p<0.05$ versus grupo Controle; $\left({ }^{* *}\right) p<0.01$ versus grupo Controle; $\left({ }^{* * *}\right) p<0.001$ versus grupo Controle. u.a. unidades arbitrárias. (B) As linhagens PTC3-5 e PC-BRAF foram tratadas com $1 \mu \mathrm{g} / \mathrm{mL}$ de doxiciclina nos tempos indicados e $30 \mu \mathrm{g}$ de proteínas foram separadas por SDS-PAGE e transferidas para uma membrana de nitrocelulose. A membrana foi incubada com anti-Notch1, anti-pERK, anti-ERK e anti- $\alpha-A c t i n a$. 


\subsection{Avaliação funcional da via de sinalização Notch na ativação oncogênica da via MAPK}

Para avaliar a atividade funcional da via de sinalização Notch na linhagem PC$\mathrm{BRAF}$, transfectamos transientemente o vetor contendo quatro elementos responsivos ao CBF1 fusionado ao gene repórter luciferase (4xCBF1-Luc), após a ativação oncogênica observamos um aumento na atividade do gene repórter luciferase (Figura 8A), demonstrando a ativação canônica da via Notch pelo oncogene BRAFT1799A. Além disso, a indução do oncogene RET/PTC3 e BRAFT1799A aumentou a expressão do gene HES1 48 e 72 horas após a ativação dos oncogenes nas linhagens PTC3-5 e PC-BRAF, respectivamente (Figura 8B). Observamos um aumento na expressão gênica de Jag1, um ligante dos receptores Notch, 72 horas após a ativação do oncogene BRAFT1799A e 24 horas após a ativação do oncogene RET/PTC3-5 (Figura 8B). 
Figura 8 - Os oncogenes RET/PTC3 e BRAFT1799A ativam a via canônica da sinalização Notch em célula folicular tiroidiana.

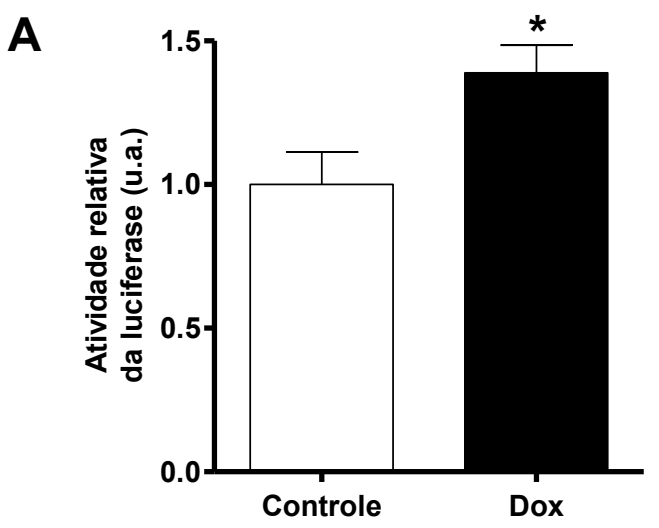

B

PTC3-5
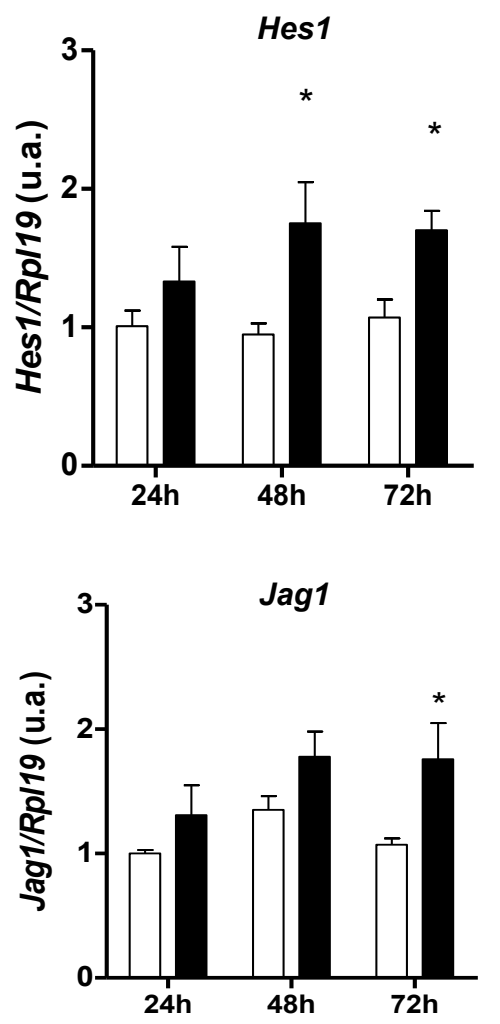

Controle
PC-BRAF
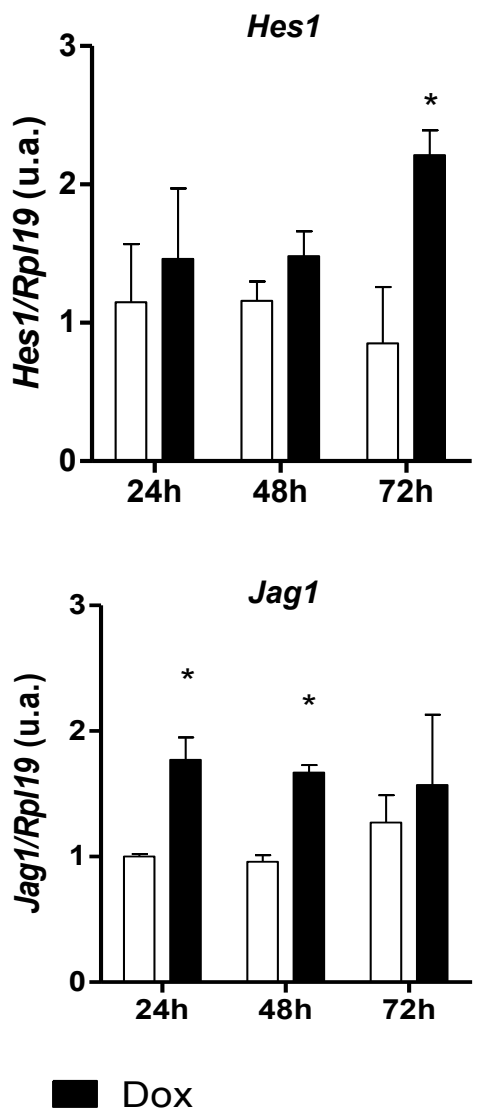

(A) A linhagem PC-BRAF foi co-transfectada com os vetores 4xCBF-Luc e pRL-CMV, tratada com 1 $\mu \mathrm{g} / \mathrm{mL}$ de doxiciclina (Dox), cultivada por $72 \mathrm{~h}$ e a atividade da via Notch foi analisada utilizando luciferase como gene repórter. Dados da atividade da luciferase normalizados pela atividade da renila. (B) As linhagens PTC3-5 e PC-BRAF foram tratadas com $1 \mu \mathrm{g} / \mathrm{mL}$ de doxiciclina nos tempos indicados e a análise da expressão gênica de Hes1 e Jag1 foi realizada por PCR em tempo real. Dados expressos como média $\pm \operatorname{EP}(\mathrm{n}=3) .\left(^{*}\right) p<0.05$ versus grupo Controle. u.a. unidades arbitrárias. 


\subsection{Efeito da inibição da via de sinalização MAPK sobre a expressão de NOTCH1 em células derivadas de carcinoma papilífero de tiroide}

Para avaliar se a regulação da sinalização Notch em células derivadas de carcinoma papilífero de tiroide é dependente da via MAPK, as linhagens TPC-1 e BCPAP, que possuem o rearranjo RET/PTC1 e a mutação BRAFT1799A, respectivamente, foram tratadas com inibidores de MEK1 PD98059 (20 $\mu \mathrm{M})$ e MEK1/2 U0126 (10 $\mu \mathrm{M})$, e a expressão gênica de NOTCH1 e HES1 foram avaliadas após 48 horas de tratamento. A expressão gênica de NOTCH1 e HES1 diminuíram após a supressão de MEK1/2 na linhagem celular TPC-1 (Figura 9A e 9B). Em contraste, na linhagem BCPAP a expressão gênica de NOTCH1 e HES1 não foram moduladas após a inibição da via MAPK (Figura 9A e 9B). Testamos a hipótese de que a inibição farmacológica de BRAFT1799A pelo inibidor PLX4032 na linhagem BCPAP regularia a sinalização Notch. Após a inibição de BRAF não observamos modulação na expressão de NOTCH1 na célula BCPAP (Figura 9A e 9B). 
Figura 9 - A modulação da sinalização Notch pela inibição de MEK é específica na linhagem TPC-1.

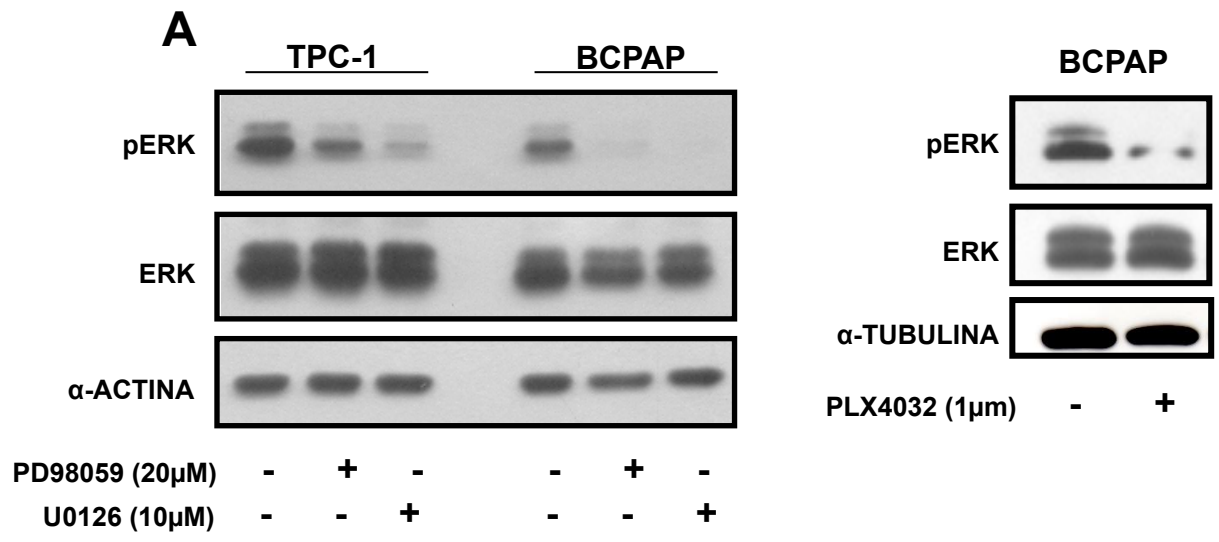

B

TPC-1

BCPAP

BCPAP

NOTCH1

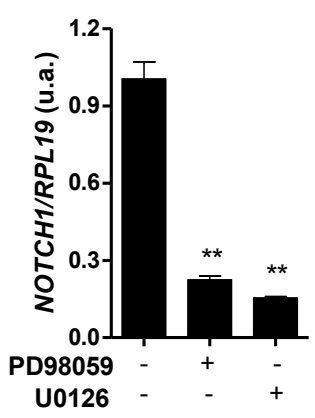

NOTCH1

NOTCH1

HES1


(A) As linhagens TPC-1 e BCPAP foram semeadas em triplicata e tratadas com os inibidores de MEK1 PD98059 $(20 \mu \mathrm{M})$ e MEK1/2 U0126 $(10 \mu \mathrm{M})$ por 48 horas. Trinta microgramas de proteínas foram separadas por SDS-PAGE e transferidas para uma membrana de nitrocelulose. A membrana foi incubada com anti-pERK, anti-ERK e anti-a-Actina. (B) Utilizando o mesmo tratamento indicado na figura $\mathbf{A}$ a análise da expressão gênica de NOTCH1 e HES1 foi realizada por PCR em tempo real. Dados expressos como média $\left.\pm \operatorname{EP}(\mathrm{n}=3) .{ }^{(* *}\right) p<0.01$ versus grupo Controle; $\left({ }^{* * *}\right) p<0.001$ versus grupo Controle. u.a. unidades arbitrárias. 


\subsection{Expressão de NOTCH1 em amostras de carcinoma papilífero de tiroide}

Camundongos transgênicos com expressão do gene BRAFT1799A na glândula tireoide, responsivo ao promotor de tiroglobulina, apresentaram arquitetura semelhante ao observado no carcinoma papilífero humano (núcleos menos corados, presença de papilas, arquitetura folicular comprometida e presença de colóide distribuído de maneira irregular) e maior positividade na imunomarcação de Notch1, indicando uma maior expressão proteica de Notch1 no modelo in vivo de carcinoma papilífero (Figura 10A). Em amostras pareadas não tumoral e tumoral de carcinoma papilífero de tiroide humano, 64\% (9/14) apresentaram aumento na expressão gênica de NOTCH1 (Figura 10B). Na análise da expressão proteica de NOTCH1 por Western blotting observamos níveis de expressão heterogênea entre as amostras não tumoral. No entanto, as amostras de carcinoma papilífero de tiroide apresentaram altos níveis de expressão proteica de NOTCH1 quando comparadas com as amostras não tumorais (Figura 10B). 
Figura 10 - A expressão de Notch1 está elevada em camundongos transgênicos e no carcinoma papilífero de tiroide.
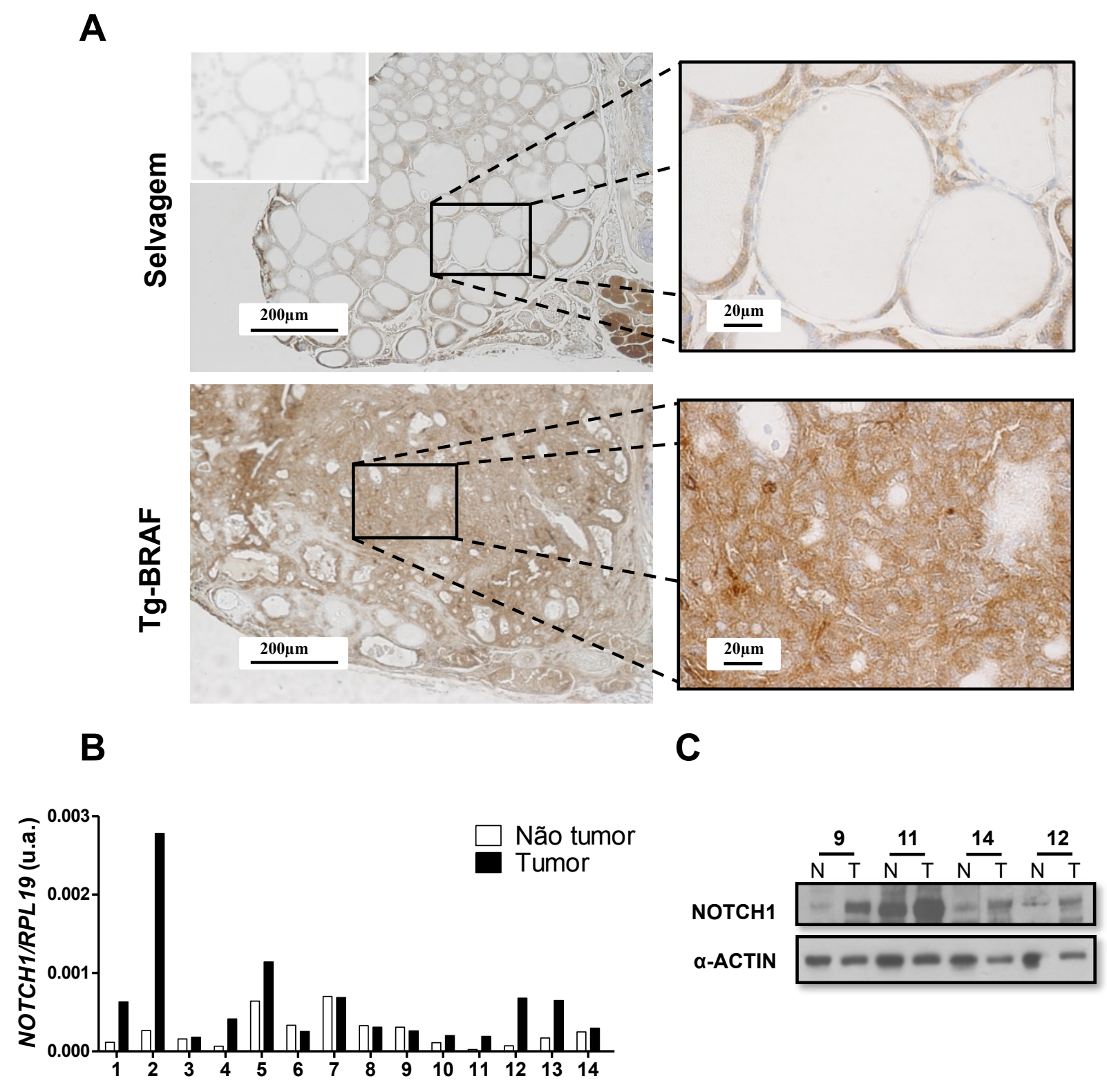

(A) Imagem representativa de imunomarcação de Notch1 em tiroide de camundongos selvagens e TgBRAF. A contra coloração foi realizada com Hematoxilina de Gill. (B) O RNA total de amostras pareadas de carcinoma papilífero de tiroide foi extraído e a análise da expressão gênica de NOTCH1 foi realizada por PCR em tempo real. u.a. unidades arbitrárias. (C) Proteína total foi extraída das amostras indicadas e $30 \mu \mathrm{g}$ de proteínas foram separadas por SDS-PAGE e transferidas para uma membrana de nitrocelulose. A membrana foi incubada com anti-NOTCH1 e anti-a-ACTINA. 


\subsection{Regulação da diferenciação celular por Notch1}

Para avaliar o efeito da sinalização Notch na diferenciação da célula folicular tiroidiana e no carcinoma papilífero de tiroide, analisamos a expressão do transportador simporter de iodeto NIS (do inglês, sodium/iodide symporter). A análise imunohistoquímica da expressão de $\mathrm{NOTCH} 1$ no micro arranjo de tecido derivados de carcinoma papilífero de tiroide não apresentou relação aparente com a imunomarcação de NIS (Tabela 4). A Figura 11 mostra uma imagem representativa com forte imunomarcação de NIS e fraca imunomarcação de NOTCH1. Para avaliar o efeito isolado da sinalização Notch na expressão de NIS, utilizamos a linhagem PC-NOTCH1 com superexpressão do domínio intracelular de NOTCH1. Utilizando a técnica de Western blotting observamos um aumento na expressão proteica de NIS na linhagem PC-NOTCH1 (Figura 12A).

\section{Tabela 4 - Análise imunohistoquímica da expressão de NIS e NOTCH1 em amostras de carcinoma papilífero de tiroide.}

\begin{tabular}{c|cccccc}
\hline \multirow{5}{*}{} & \multicolumn{7}{c}{ NOTCH1 } \\
\cline { 2 - 7 } & & - & + & ++ & +++ & $\mathrm{n}$ \\
\cline { 2 - 7 } & - & 0 & 0 & 0 & 0 & 0 \\
\cline { 2 - 7 } & + & 0 & 1 & 2 & 0 & 3 \\
\cline { 2 - 7 } & ++ & 0 & 4 & 1 & 1 & 6 \\
\cline { 2 - 7 } & +++ & 1 & 4 & 4 & 2 & 11 \\
\cline { 2 - 7 } & & 1 & 9 & 7 & 3 & $\mathrm{n}=20$ \\
\hline
\end{tabular}


Figura 11 - A expressão proteica de NOTCH1 não está relacionada com os níveis proteicos de NIS no carcinoma papilífero de tiroide.


A análise da expressão proteica de NIS e NOTCH1 foi realizada por imunohistoquimica em amostras derivadas de carcinoma papilífero de tiroide. A contra coloração foi realizada com Hematoxilina de Gill.

\subsection{Sinalização Notch e seu papel na regulação da proliferação de célula folicular tiroidiana}

Para entender o papel isolado da sinalização Notch na proliferação celular em célula folicular normal de tiroide, transfectamos a linhagem PCCL3 com o vetor pBABEvazio ou pBABE-NOTCH1, gerando as linhagens PC- $\varnothing$ e PC-NOTCH1, respectivamente. Confirmamos o aumento da expressão proteica do domínio intracelular de Notch1 e do gene alvo da via Notch (Hes1) na linhagem PC-NOTCH1 (Figura 12A e 12B). A análise da proliferação celular não apresentou diferença entre os grupos (Figura 12C), dado corroborado pela não alteração na expressão de Ciclina D1 (Figura 12A), proteína envolvida na transição G0/G1 do ciclo celular. 
Figura 12 - Superexpressão do domínio intracelular de Notch1 não modula a proliferação de célula normal de tiroide - PCCL3.

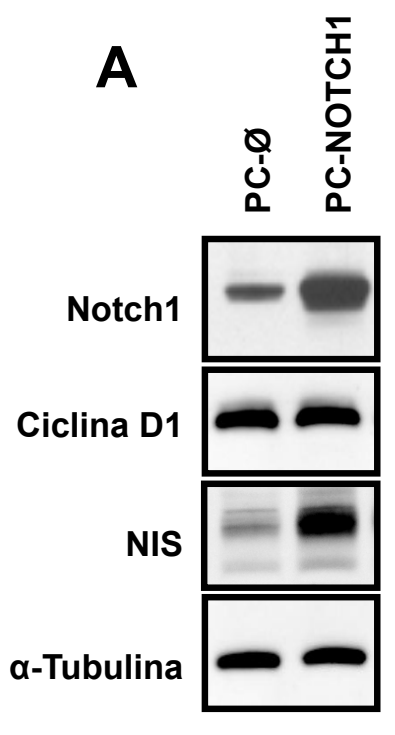

B
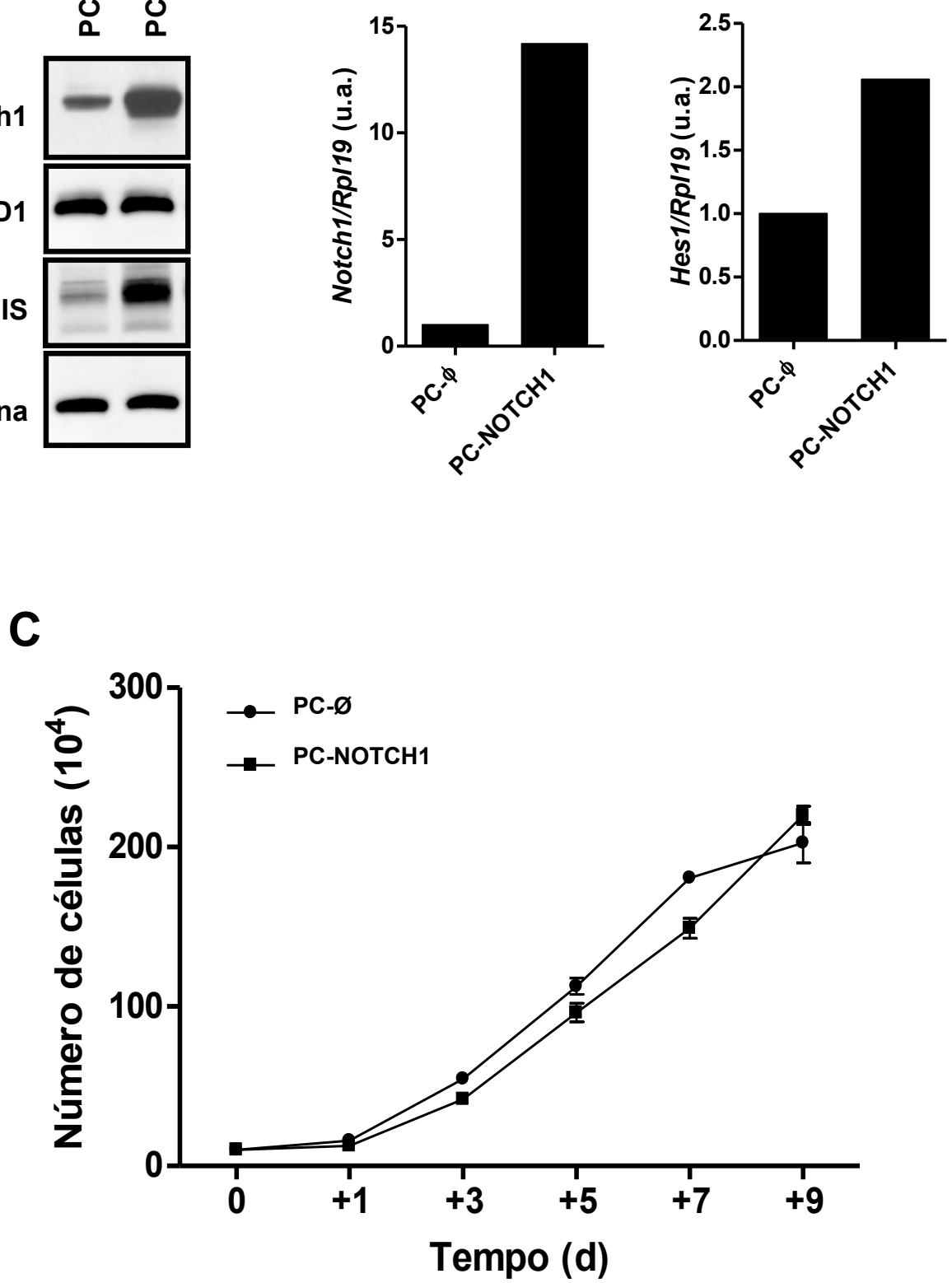

(A) Proteína total das linhagens PC- $\Phi$ e PC-NOTCH1 foram separadas por SDS-PAGE e analisadas por Western blotting com os anticorpos indicados. O anticorpo NIS detectou duas bandas correspondentes ao tamanho aproximado de 70-80 kDa, representando o grau de glicosilação da proteína. (B) RNA total foi extraído e usado para síntese de CDNA, em seguida o PCR em tempo real foi realizado para determinar os níveis de Notch1 e Hes1. u.a. unidades arbitrárias. (C) PC-Ф e PC-NOTCH1 foram semeadas e o número de células foi determinado nos tempos indicados. Dados expressos como média \pm E.P $(n=3)$. 


\subsection{Efeito da inibição da sinalização Notch na proliferação celular de células derivadas de carcinoma papilífero de tiroide}

Utilizamos o inibidor de gama secretase GSI para entender o papel da sinalização Notch na proliferação celular de células derivadas de carcinoma papilífero de tiroide. O bloqueio farmacológico de gama secretase impede a clivagem proteolítica dos receptores Notch, 48 horas após o tratamento com GSI observamos um acúmulo de NOTCH1 na membrana plasmática de células TPC-1 (Figura 13A). Confirmamos o efeito inibitório induzido de GSI na via Notch pela avaliação da expressão gênica de HES1, gene alvo da via da via Notch (Figura 13B). O tratamento das linhagens TPC-1 e BCPAP com GSI apresentou um efeito dose dependente na redução da porcentagem de células viáveis (Figura 14A), observamos também um redução do número de células pela análise da curva de crescimento 48 horas após a inibição da sinalização Notch (Figura 14B). 
Figura 13 - Inibição de gama secretase acumula NOTCH1 na membrana plasmática e diminui a expressão de HES1 na linhagem TPC-1 de carcinoma papilífero de tiroide.

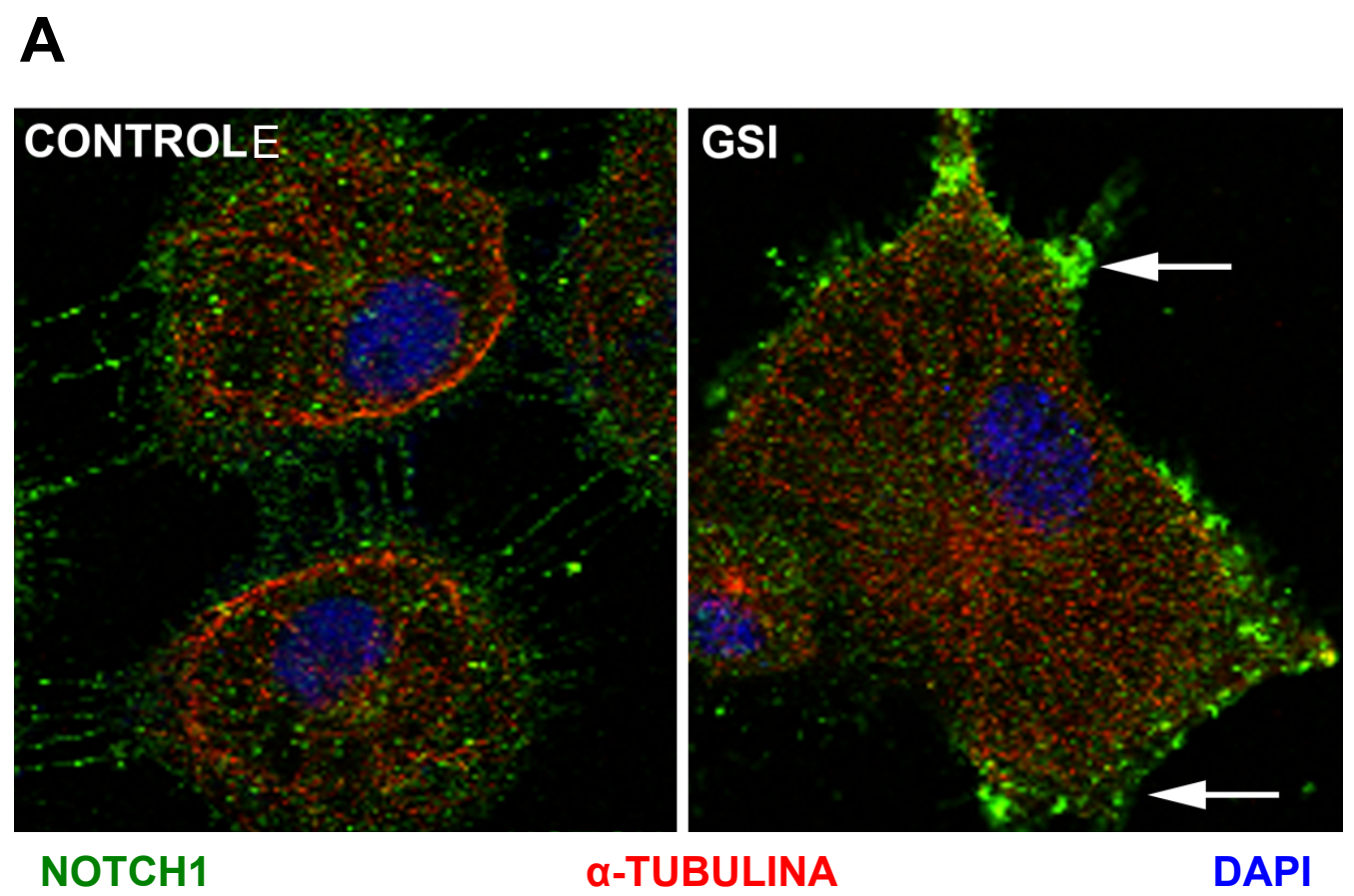

B

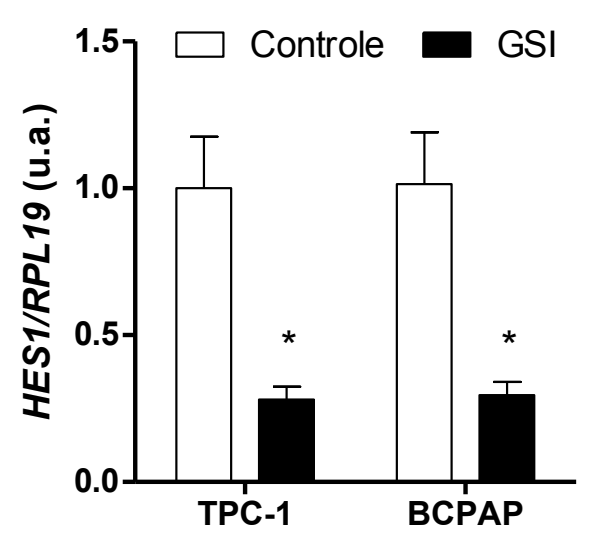

(A) A linhagem TPC-1 foi tratada com GSI $(1 \mu \mathrm{M})$ por 48 horas, a imunomarcação foi realizada com os anticorpos anti-NOTCH1; anti-a-TUBULINA e o núcleo foi marcado com DAPI. A sobreposição das imagens evidencia o acúmulo de NOTCH1 full-lenght na membrana plasmática. (B) As linhagens TPC-1 e BCPAP foram tratadas com GSI $(1 \mu \mathrm{M})$ por 48 horas e a análise da expressão gênica de HES1 foi realizada por PCR em tempo real. Dados expressos como media \pm EP $(n=3) .\left({ }^{*}\right) p<0.05$ versus grupo controle. Controle. u.a. unidades arbitrárias. 
Figura 14 - Inibição da sinalização Notch diminui a proliferação em células de carcinoma papilífero de tiroide.

$\mathbf{A}$

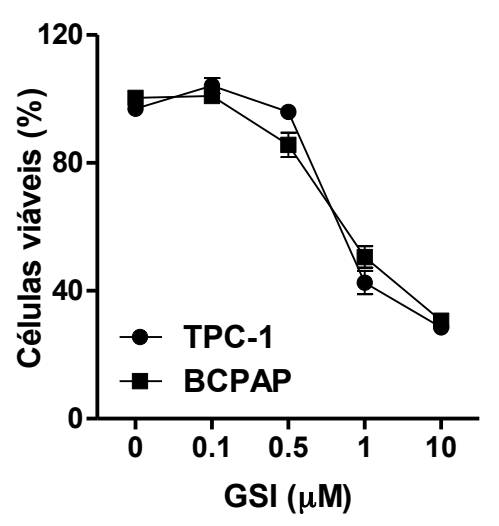

TPC-1

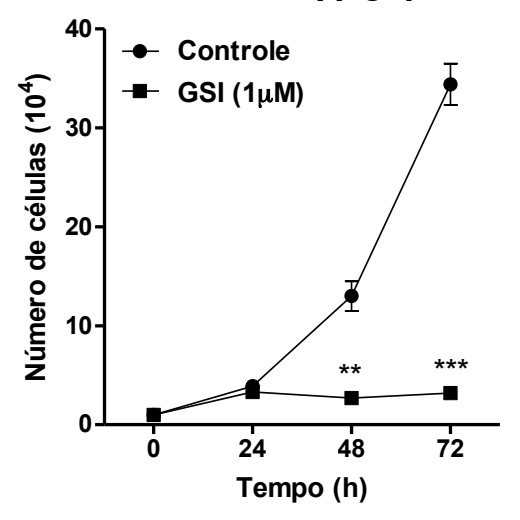

BCPAP

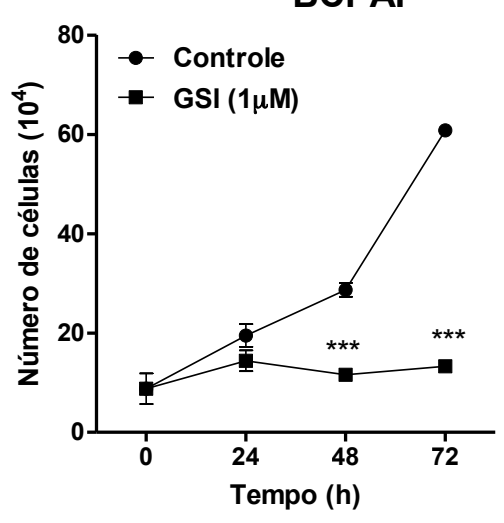

(A) As linhagens TPC-1 e BCPAP foram semeadas e tratadas com as concentrações indicadas de GSI por 48 horas e o percentual de células viáveis foi avaliado pela técnica MTT. (B) As linhagens TPC-1 e BCPAP foram semeadas e tratadas com GSI $(1 \mu \mathrm{M})$ e o número total de células foi determinado nos tempos indicados. Dados expressos como media \pm EP $(n=3) .\left(^{* *}\right) p<0.01$ versus grupo controle; $\left({ }^{* * *}\right)$ $p<0.001$ versus grupo Controle. u.a. unidades arbitrárias.

A análise do percentual de células nas fases do ciclo celular por citômetria de fluxo demonstrou um aumento nas fases $\mathrm{G} 2 / \mathrm{M}$ com uma concomitante redução no percentual de células nas fases $\mathrm{G} 1$ e $S$ do ciclo celular após 24 e 48 horas de tratamento com GSI $(1 \mu \mathrm{M})$ na linhagem TPC-1 e um aumento em sub-G1 nas linhagens carcinoma papilífero de tiroide, com um maior efeito na linhagem BCPAP (Figura 15A). Além disso, GSI regulou a expressão de genes relacionados com o controle do ciclo celular, aumentou a expressão gênica de CDKN1A, CDKN1B e diminuiu a expressão gênica de CCND1, MCM6, CKS2, e MAD2L na linhagem TPC-1 (Figura 15B), um resultado similar foi observado na linhagem BCPAP com uma redução na expressão gênica de CDKN1A (Figure 14B). 
Figura 15 - A inibição da sinalização Notch promove parada em G2/M e regula genes envolvidos no controle do ciclo celular.

A

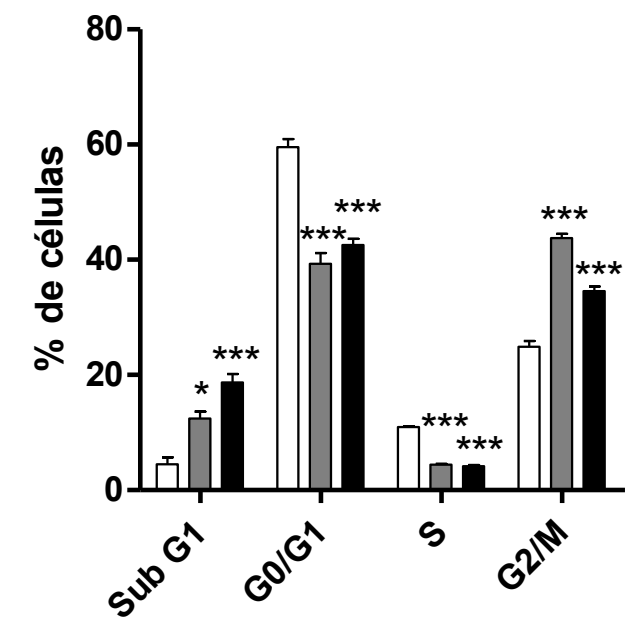

B

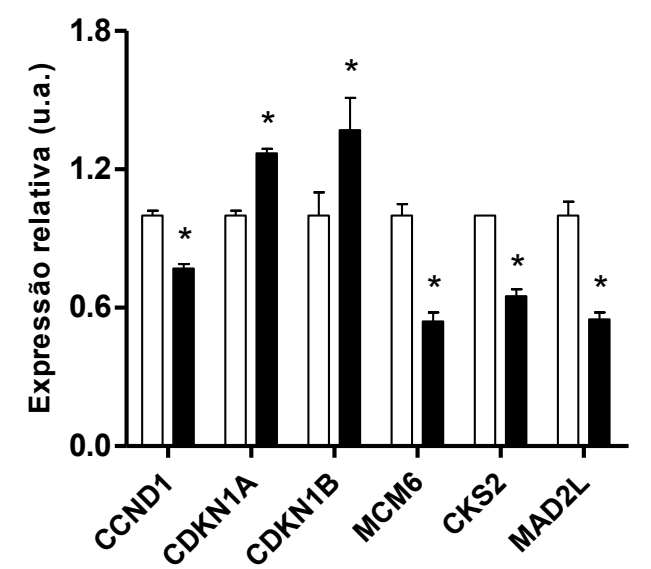

BCPAP

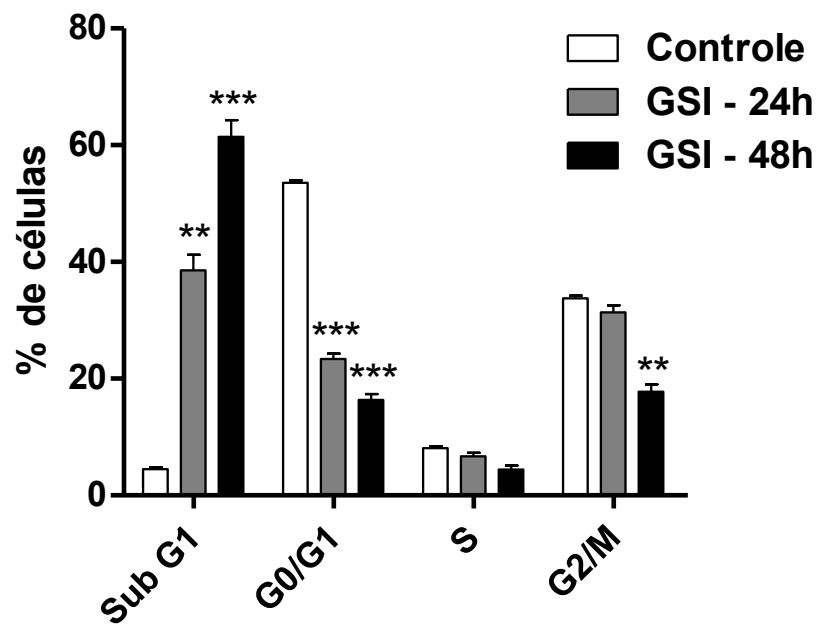

BCPAP



(A) As linhagens TPC-1 e BCPAP foram tratadas com GSI (1 $\mu \mathrm{M})$ e após 24 e 48 horas a análise do ciclo celular foi realizada em citometria de fluxo. (B) As linhagens TPC-1 e BCPAP foram tratadas GSI $(1 \mu \mathrm{M})$ e após 48 horas a análise da expressão gênica de CCND1, CDKN1A, CDKN1B, MCM6, CKS2 e MAD2L foi realizada por PCR em tempo real. Dados expressos como média $\pm \operatorname{EP}(\mathrm{n}=3) .\left(^{*}\right) p<0.05$ versus grupo Controle. $\left({ }^{* *}\right) p<0.01$ versus grupo Controle. ${ }^{(* *)} p<0.001$ versus grupo Controle. 
A redução no percentual de células viáveis e o aumento na fração de células Sub-G1 na análise do ciclo celular após o tratamento com GSI mostra que a inibição da via de sinalização Notch é importante na regulação da morte celular. Dessa forma, nos questionamos se a inibição da sinalização Notch induz apoptose em células de carcinoma papilífero de tiroide. Para determinar o percentual de células apoptóticas tratamos as linhagens TPC-1 e BCPAP com GSI ( $1 \mu \mathrm{M})$ por 24 e 48 horas e realizamos a dupla marcação com iodeto de propídeo e Anexina- $V$ conjugada com FITC. A linhagem BCPAP apresentou aumento no número de células apoptóticas 24 e 48 horas após o tratamento, enquanto a célula TPC-1 apresentou aumento 48 horas após a inibição de gama secretase (Figura 16A e 16B). 
Figura 16 - Bloqueio da sinalização Notch induz apoptose em células derivadas de carcinoma papilífero de tiroide.

A

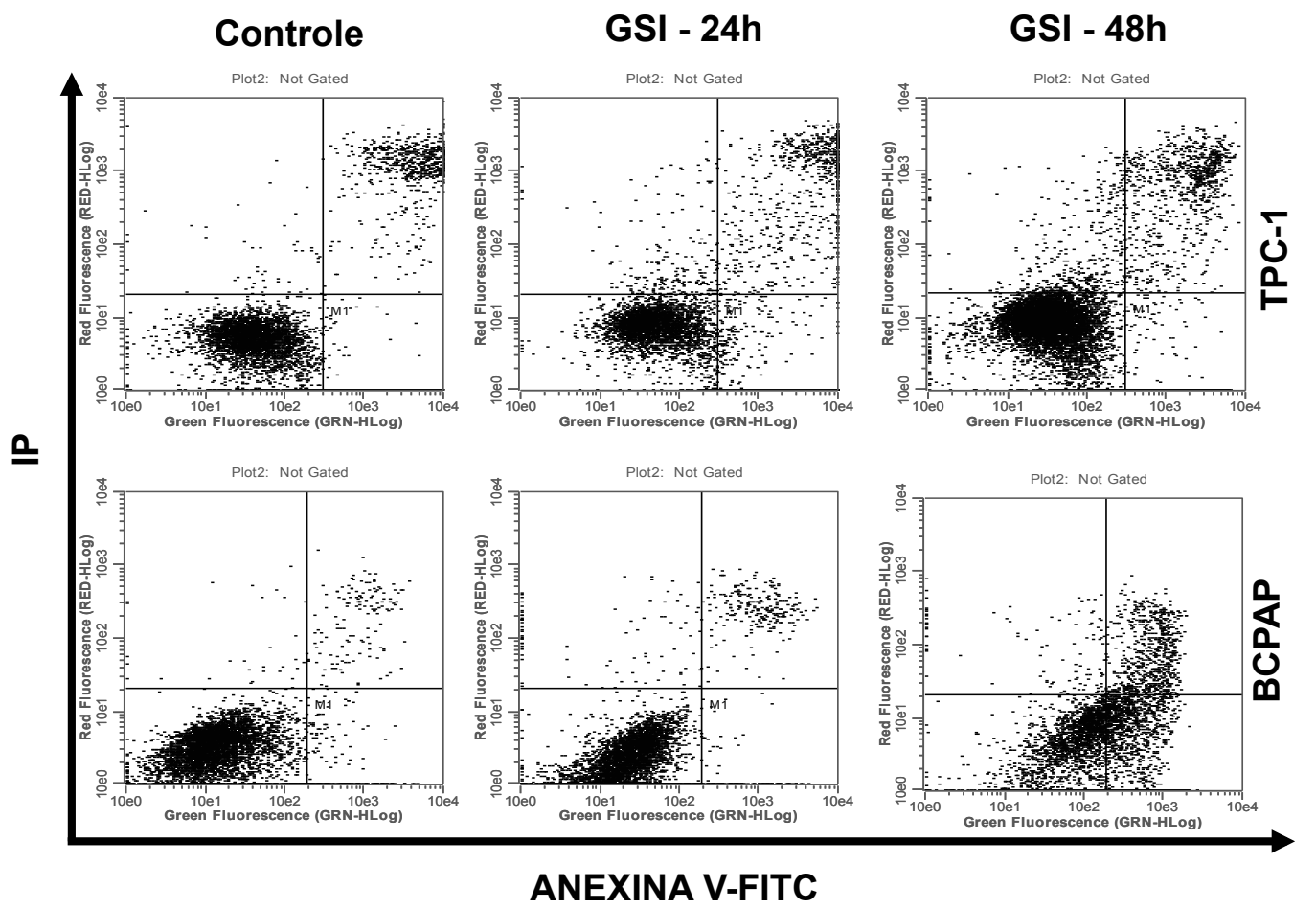

B

TPC-1

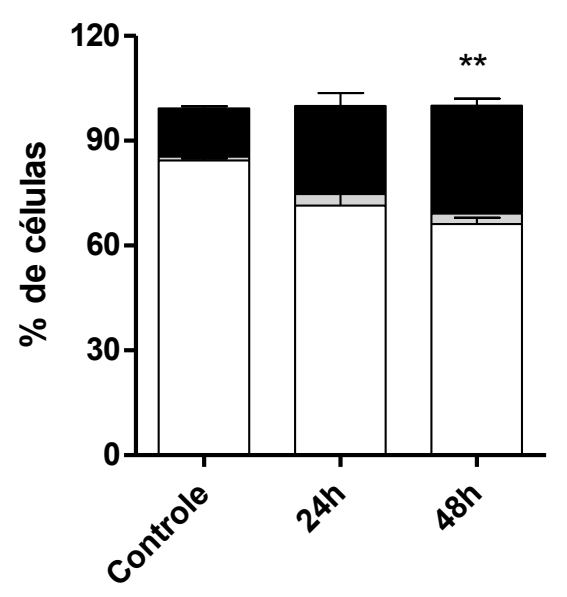

BCPAP

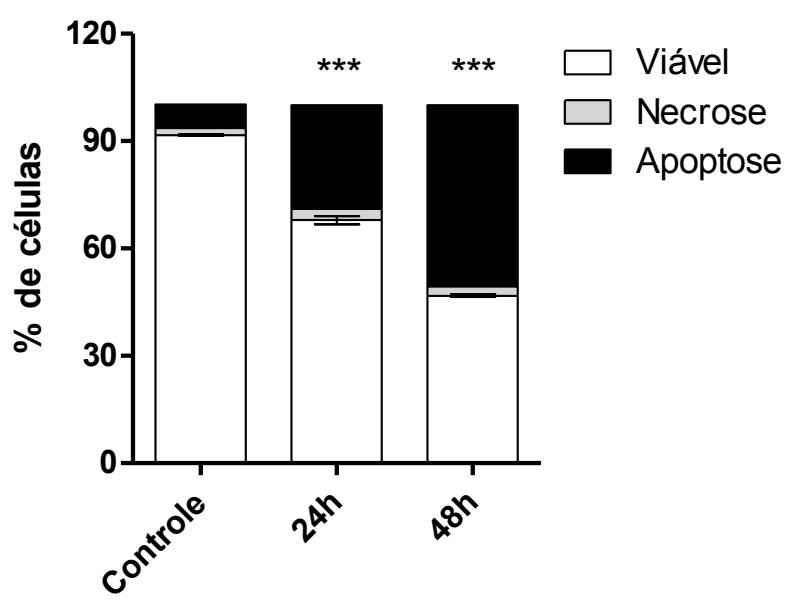

(A e B) As linhagens TPC-1 e BCPAP foram tratadas com GSI $(1 \mu \mathrm{M})$ nos tempos indicados e o percentual de células apoptóticas foram quantificadas por citometria de fluxo. Dados expressos como média \pm EP $(\mathrm{n}=3) .\left({ }^{* *}\right) p<0.01$ versus grupo Controle; $\left({ }^{* * *}\right) p<0.001$ versus grupo Controle. 
Para excluir o possível efeito off-target induzido pelo inibidor farmacológico da sinalização Notch, utilizamos a estratégia de silenciamento gênico de NOTCH1 por RNA de interferência. A transfecção transiente de siNOTCH1 (siN1) na linhagem TPC-1 diminuiu a expressão proteica de NOTCH1 (Figura 17A), confirmando a eficiência do silenciamento gênico. A análise do número de células demonstrou uma redução após 72 horas de silenciamento do gene NOTCH1 (Figura 17B) e aumentou a porcentagem de células apoptóticas (Figura 17C), corroborando os dados prévios que a inibição farmacológica da sinalização Notch regula a proliferação celular e confirmando a importância funcional da via de sinalização Notch no carcinoma papilífero de tiroide. 
Figura 17 - Silenciamento gênico de NOTCH1 reduz a proliferação celular na linhagem TPC-1.
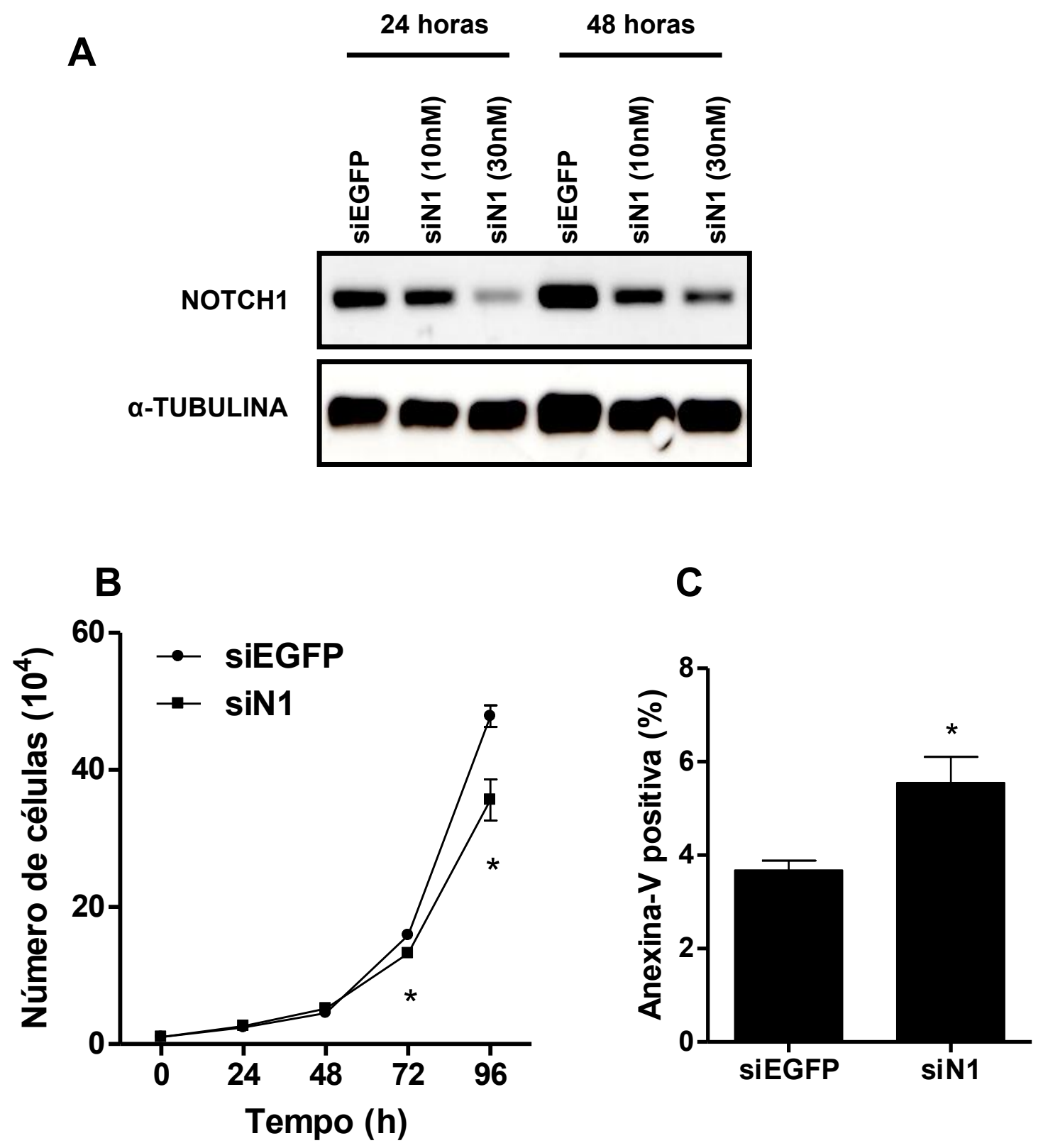

(A) Células TPC-1 foram transfectadas transientemente com o siRNA-NOTCH1 (siN1) (10 ou $30 \mathrm{nM}$ ) e siRNA-GFE (siEGP) (30 nM), 48 horas após a transfecção $30 \mu \mathrm{g}$ de proteínas foram separadas por SDS$P A G E$ e transferidas para uma membrana de nitrocelulose. A membrana foi incubada com anti-NOTCH-1 e anti-a-TUBULINA. (B) Células TPC-1 foram semeadas em placas de 6 poços, transfectadas com os oligos indicados (30 $\mathrm{nM}$ ) e o número de células foi determinado nos tempos indicados. (C) Células TPC-1 foram semeadas em triplicata em placas de $60 \mathrm{~mm}$, transfectadas com os oligos indicados (30 $\mathrm{nM}$ ) e ensaio de dupla marcação com Anexina-V/IP foi realizado 96 horas após a transfecção. Dados expressos como média $\pm \operatorname{EP}(\mathrm{n}=3)$. $\left(^{*}\right) P<0,05$ versus grupo Controle. 
O bloqueio da via de sinalização MAPK pelos inibidores de MEK diminuiu a porcentagem de células viáveis derivadas de carcinoma papilífero de tiroide, com maior ação antiproliferativa na linhagem BCPAP, quando comparada a linhagem TPC-1 (Figura 18). A adição de $\mathrm{GSI}$ em uma concentração reduzida $(0,1 \mu \mathrm{M})$ aumentou a ação antiproliferativa do inibidor de MEK (U0126) nas linhagens derivadas de carcinoma papilífero de tiroide (Figura 18).

Figura 18 - Inibição da sinalização Notch aumenta o efeito antiproliferativo mediado pelo bloqueio da sinalização MAPK.
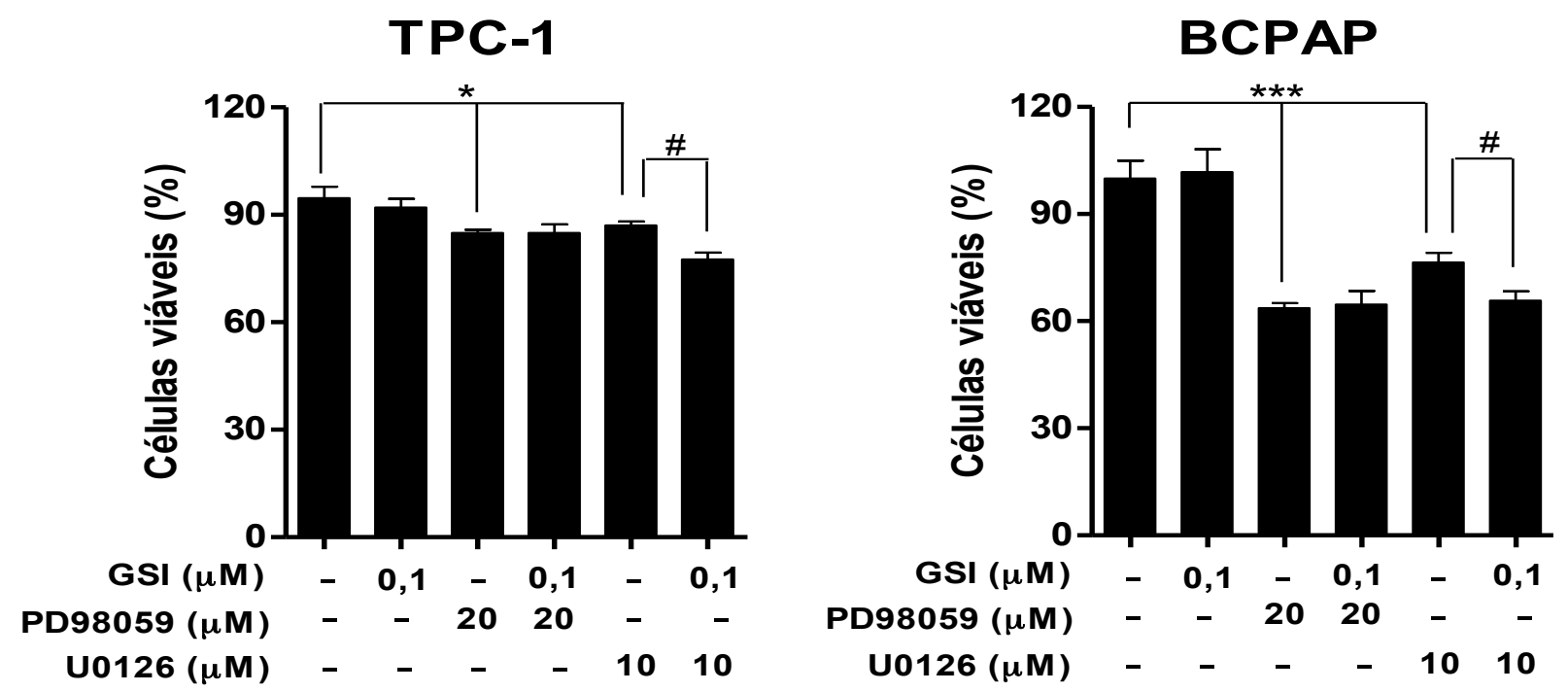

As linhagens TPC-1 e BCPAP foram tratadas com GSI $(0,1 \mu \mathrm{m})$ e inibidores de MEK PD98059 $(20 \mu \mathrm{M})$ ou U0126 (10 $\mu \mathrm{M})$, MEK1 e MEK1/2 respectivamente, após 48 horas o percentual de células viáveis foi determinado pela técnica MTT. Dados expressos como média \pm EP $(n=3) .\left({ }^{* *}\right) p<0.01 ;\left(^{* * *}\right) p<0.001 ;\left({ }^{\#}\right)$ $p<0.05$. 


\section{DISCUSSÃO}

Nesse estudo avaliamos a regulação da sinalização Notch por oncogenes frequentemente alterados no carcinoma papilífero de tiroide, o rearranjo cromossômico RET/PTC e a mutação BRAFT1799A, e sua influência no controle da diferenciação e proliferação celular. Várias linhas de evidências indicam que a sinalização Notch participa do processo de tumorigênese em neoplasias neurológicas, hematológicas e epiteliais $(67,68)$. A indução dos oncogenes RET/PTC3 ou BRAFT1799A na célula folicular tiroidiana aumentou a atividade da via de sinalização Notch. Amostras de carcinoma papilífero de tiroide e do modelo in vivo de carcinoma papilífero de tiroide em camundongos apresentaram uma elevada expressão de NOTCH1. A superexpressão de NOTCH1 em célula normal de tiroide regulou a diferenciação celular. Além disso, o bloqueio da via de sinalização Notch diminui a proliferação celular de células derivadas de carcinoma papilífero de tiroide.

Componentes da sinalização Notch estão frequentemente alterados em diversos tipos de neoplasias, no carcinoma papilífero de tiroide observamos um aumento da expressão gênica e proteica de NOTCH1, demostrando que a via de sinalização Notch está desbalanceada (27). O aumento da expressão de NOTCH1 está associado a marcadores de prognóstico desfavorável no carcinoma papilífero de tiroide, tal como, metástase linfonodal e invasão capsular (45). Alterações nos níveis de expressão de componentes da sinalização Notch, incluindo JAGGED1 e o receptor NOTCH1, também estão associados a um prognóstico desfavorável no câncer de próstata e coloretal (69, 70). Demonstrando uma potencial aplicação da sinalização Notch como um marcador molecular na prática clínica.

Alterações genéticas em efetores da via MAPK estão envolvidas nas etapas iniciais da tumorigênese do carcinoma papilífero de tiroide. A expressão dos oncogenes RET/PTC e BRAFT1799A em camundongos resulta em tumores com fenótipo semelhantes ao observado no carcinoma papilífero de tiroide humano $(64,71-75)$. Analisando o papel da ativação dos oncogenes, RET/PTC e BRAFT1799A, em célula folicular tiroidiana observamos que a via MAPK participa da regulação da via Notch. No câncer, a sinalização MAPK regula a via Jagged1/Notch e aumenta o processo de 
angiogênese em células derivadas de carcinoma epidermóide de cabeça e pescoço e promove a tumorigênese no câncer de pâncreas $(50,51)$. Além disso, a expressão transiente de $\mathrm{RAS}^{\mathrm{V} 12}$ em células embrionárias de camundongo e em fibroblastos aumenta a expressão de NOTCH1. Por outro lado, o bloqueio da sinalização Notch inibe a proliferação mediada por RAS in vitro e in vivo (48). Recentemente, camundongos transgênicos com carcionoma de pulmão induzido por RAS ${ }^{\mathrm{V} 12}$ apresentam elevada atividade da via de sinalização Notch e o bloqueio de gama secretase atenua o crescimento do tumor, por um mecanismo que envolve a ativação de fosfatases da via MAPK por Hes1, o gene alvo da via Notch (52).

Embora os oncogenes das linhagens TPC-1 (rearranjo cromossômico RET/PTC1) e BCPAP (mutação BRAFT1799A) ativem constitutivamente a sinalização MAPK outras vias de sinalização são reguladas pelos oncogenes, que pode explicar, pelo menos em parte, a diferença no comportamento biológico em carcinoma papilífero de tiroide com diferentes alterações genética. Por exemplo, o oncogene RET/PTC ativa a sinalização $\beta$-catenina e desregula o microRNA let-7, enquanto BRAFT1799A ativa a sinalização NF-KB e preferencialmente remodela a matrix extracelular $(55,76-78)$. Interessantemente, o bloqueio da sinalização MAPK por inibidores de MEK diferencialmente regulam a via Notch nas células TPC-1 e BCPAP, indicando que diferentes etapas na via MAPK controlam a expressão de NOTCH1.

O transportador de iodeto NIS é uma glicoproteína localizada na porção basolateral da membrana plasmática da célula folicular tiroidiana. Sua função é transportar o iodeto para o interior da célula folicular tiroidiana, etapa fundamental para a síntese dos hormônios tiroideanos (79). Dessa forma, a administração de iodo radioativo explora essa particularidade fisiológica da glândula tiroide no tratamento de carcinomas derivados da célula folicular. No entanto, uma característica marcante no câncer de tiroide de origem folicular é a perda de expressão de NIS, principalmente nos casos mais avançados, que contribui de forma significativa na refração a terapia com iodo radioativo (6). Observamos uma similaridade com o trabalho de Ferretti et al. (2008) que mostraram um aumento na expressão de NIS com a ativação do receptor NOTCH1 em célula folicular normal de tiroide (44). Nos tecidos de carcinoma papilífero de tiroide com imunomarcação de NOTCH1 a expressão de NIS não demonstrou 
modulação. Esses dados sugerem que a regulação da expressão de NIS no carcinoma papilífero de tiroide depende de outros eventos moleculares. De fato, o TGF- $\beta$ é secretado pela célula tumoral e age de modo autócrino gerando um looping repressor da expressão de NIS em célula folicular tiroidiana com ativação do oncogene BRAFT1799A (80).

A análise do papel isolado da sinalização Notch na proliferação de célula folicular normal de tiroide com expressão ectópica do domínio intracelular de NOTCH1 (linhagem PC-NOTCH1) não apresentou modulação. Em poucos tipos de células a via de sinalização Notch isoladamente promove a tumorigênese. A transformação maligna in vitro induzida pela expressão ectópica do domínio intracelular de Notch1, ativando constitutivamente a via, pode ocorrer em conjunto com outros oncogenes, tais como adenovirus E1A, papiloma vírus humano (HPV) E6 e E7, RAS e MYC (48, 49, 81-83). Dessa forma, embora a sinalização Notch possa contribuir para o processo de tumorigênese é necessário outros eventos moleculares para o aumento da proliferação celular.

A proliferação celular atua pelo fino balanço entre divisão e morte celular, a alteração em um desses eventos é um passo crítico para a proliferação celular. A sinalização Notch regula diretamente genes envolvidos no controle do ciclo celular, tais como, c-MYC, MCM2 and MCM6, CDKN1A, e CCND1, que pode explicar, pelo menos parcialmente, a diminuição da proliferação após o bloqueio de gama secretase em células derivadas de carcinoma papilífero de tiroide (34, 84-86). Embora estudos tenham demonstrado que o bloqueio da sinalização Notch induza morte celular em diferentes tipos de câncer, o mecanismo molecular na indução da apoptose por esse componente ainda continua pouco elucidado. Em linhagens de câncer de mama, GSI diminui a expressão das proteínas anti-apoptóticas XIAP e Bcl-2 e aumenta a expressão das proteínas pró-apoptóticas Bax e Bad de modo dose dependente (87). Além disso, o silenciamento gênico de NOTCH1 por RNA de interferência diminui a expressão de Bcl-2 e Bcl-xL em linhagens de câncer pancreático e de mama e induz parada em G2/M no ciclo celular, mecanismo que envolve a redução da expressão de Ciclina B1 e sua localização nuclear em linhagem de sarcoma de Kaposis $(88,89)$. 
A parada na fase $\mathrm{G} 2 / \mathrm{M}$ do ciclo celular pode ser induzida por diversos fatores, os mais conhecidos são a radiação ionizante e quimioterápicos derivados da vinca (por exemplo, vincristina, vindesina e vimblastina) e taxanos (por exemplo, paclitaxel e docetaxel), por conseguinte estratégias que induzem parada no ciclo celular na fase G2/M são importantes ferramentas no controle da proliferação de células tumorais (90). A parada em G2/M é resultado do acionamento do ponto de checagem mitótico induzido pela ativação do heterodímero Ciclina B/Cdk1 (do inglês, Cyclin-dependent kinase 1), formalmente conhecido como fator promotor da mitose. Se a célula tetraplóide conseguir escapar do ponto de checagem mitótico e sobreviver, na próxima divisão celular às cromátides irmãs podem ser segregadas com conteúdo desbalanceado de DNA gerando células aneuplóides. Um segundo destino para a célula é a ativação da cascata apoptótica e consequente morte celular (91, 92). Em nosso modelo observamos uma marcante elevação na porcentagem de células em G2/M e de células apotóticas após a inibição da sinalização Notch, sugerindo que o ponto de checagem mitótico está integro e fortalecendo a ideia de que a sinalização Notch é um potencial alvo terapêutico no câncer. Efeito semelhante é observado em glioma e em câncer de mama com inibição farmacológica ou silenciamento gênico da sinalização Notch $(93,94)$. Dessa forma, a inibição da sinalização Notch modula genes que controlam o ciclo celular e apoptose, que por sua vez, diminui a proliferação de células tumorais.

Embora o mecanismo exato ainda não seja conhecido, inibidores de gama secretase podem ter um efeito off-target inibindo o proteasoma e contribuindo para a regulação da divisão celular (95). No entanto, confirmamos a importância funcional na regulação da proliferação da via Notch pelo silenciamento gênico de NOTCH1. A menor eficácia na diminuição da proliferação celular pelo silenciamento gênico quando comparada ao inibidor de gama secretase pode ser atribuída a dois fatores. O inibidor de gama secretase tem como alvo todos receptores da família Notch (Notch1-4), pois todos dependem do sistema de clivagem proteolítica mediado pelo complexo gama secretase para liberação do domínio intracelular e consequente ação biológica (31). Além disso, o silenciamento gênico depende da eficiência da transfecção enquanto inibidores farmacológicos atingem facilmente todas as células (93). 
Inibidores de proteínas quinase com peso molecular menor que $1 \mathrm{KDa}$, denominado "pequenas moléculas", tem sido alvo de intensa investigação no tratamento do câncer. No câncer de tiroide a sinalização MAPK é um potencial alvo terapêutico e estudos pré-clínicos mostram que a inibição da via de sinalização MAPK diminui o crescimento do tumor e restaura a captação de iodo $(16,73,96)$. Inibidores de gama secretase estão em testes clínicos em diferentes tipos de câncer e peptídeos permeáveis a membrana plasmática que bloqueiam a formação do complexo de transcrição de Notch inibem a oncogênese induzida pela mutação em Notch1 em leucemia linfoblástica aguda de células T em modelo animal (97-99). A concepção de regular um alvo específico em uma célula tumoral é consistente com o princípio cardinal da farmacologia: a especificidade. No entanto, diversos estudos mostram que o tratamento com um único agente frequentemente não mostra um benefício significativo, apresentando recidiva da doença ou resistência ao agente quimioterapêutico (100). A identificação de drogas com efeito sinérgico pode reduzir os efeitos colaterais, por meio da redução da dose administrada e consequentemente da toxicidade, e aumentar a eficácia terapêutica (101). Essa é uma estratégia clinicamente relevante e diferentes moléculas inibidoras de gama secretase em combinação com outros agentes quimioterapêuticos estão em teste clínico em tumores sólidos e hematológicos (98, 102). O extensivo conhecimento do crosstalk da via Notch com outras vias de sinalização, principalmente a via MAPK que está frequentemente alterada em diversos tipos de neoplasias e é a principal via oncogênica no câncer de tiroide, tem grande utilidade no desenvolvimento e identificação de novas combinações terapêuticas no tratamento do câncer. 


\section{CONCLUSÕES}

$\checkmark$ A via de sinalização Notch é regulada pela ativação dos oncogenes RET/PTC e BRAFT1799A em célula folicular de tiroide in vitro.

$\checkmark \mathrm{O}$ receptor NOTCH1 apresenta uma elevada expressão proteica em amostras de carcinoma papilífero de tiroide humana e em camundongos transgênicos com mutação BRAFT1799A na glândula tiroide.

$\checkmark$ A expressão constitutiva de Notch1 regula positivamente a expressão proteica de NIS em célula folicular normal de tiroide.

$\checkmark$ A via de sinalização Notch exerce um importante papel no controle da proliferação celular no carcinoma papilífero de tiroide, esses dados sugerem que a inibição da sinalização Notch pode ser uma potencial terapia adjuvante no câncer de tiroide originados da ativação oncogênica da via MAPK. 


\section{REFERÊNCIAS ${ }^{1}$}

1.Hegedus L. Clinical practice. The thyroid nodule. N Engl J Med. 2004 Oct 21;351(17):1764-71.

2.Hedinger C. Histology thyping of thyroid tumours. 2nd ed. Berlin: Springer-Verlog; 1998.

3.Davies L, Welch HG. Increasing incidence of thyroid cancer in the United States, 1973-2002. JAMA. 2006 May 10;295(18):2164-7.

4.Jemal A, Siegel R, Xu J, Ward E. Cancer statistics, 2010. CA Cancer J Clin. 2010 Sep-Oct;60(5):277-300.

5.Instituto Nacional de Câncer (INCA). José Alencar Gomes da Silva. Estimativa 2012: incidência de câncer no Brasil. Rio de Janeiro; 2011.

6.Nikiforov YE, Nikiforova MN. Molecular genetics and diagnosis of thyroid cancer. Nat Rev Endocrinol. 2011 Oct; 7(10):569-80.

7.Brenner H. Long-term survival rates of cancer patients achieved by the end of the 20th century: a period analysis. Lancet. 2002 Oct 12;360(9340):1131-5.

8.Durante C, Haddy N, Baudin E, Leboulleux S, Hartl D, Travagli JP, et al. Long-term outcome of 444 patients with distant metastases from papillary and follicular thyroid carcinoma: benefits and limits of radioiodine therapy. J Clin Endocrinol Metab. 2006 Aug;91(8):2892-9.

9.Vogelstein B, Kinzler KW. Cancer genes and the pathways they control. Nat Med. 2004 Aug;10(8):789-99.

10.Lemmon MA, Schlessinger J. Cell signaling by receptor tyrosine kinases. Cell. 2010 Jun 25;141(7):1117-34.

11.Robinson DR, Wu YM, Lin SF. The protein tyrosine kinase family of the human genome. Oncogene. 2000 Nov 20;19(49):5548-57.

12.Krause DS, Van Etten RA. Tyrosine kinases as targets for cancer therapy. N Engl J Med. 2005 Jul 14;353(2):172-87.

\footnotetext{
1 De acordo com: International Committee of Medical Journal Editors. [Internet]. Uniform requirements for manuscripts submitted to Biomedical Jounals: sample references. [updated 2011 Jul 15]. Available from: http://www.icmje.org.
} 
13.Fusco A, Grieco M, Santoro M, Berlingieri MT, Pilotti S, Pierotti MA, et al. A new oncogene in human thyroid papillary carcinomas and their lymph-nodal metastases. Nature. 1987 Jul 9-15;328(6126):170-2.

14.Fusco A, Santoro M. 20 years of RET/PTC in thyroid cancer: clinico-pathological correlations. Arq Bras Endocrinol Metabol. 2007 Jul;51(5):731-5.

15.Grieco M, Santoro M, Berlingieri MT, Melillo RM, Donghi R, Bongarzone I, et al. PTC is a novel rearranged form of the ret proto-oncogene and is frequently detected in vivo in human thyroid papillary carcinomas. Cell. 1990 Feb 23;60(4):557-63.

16.Wells SA, Jr., Santoro M. Targeting the RET pathway in thyroid cancer. Clin Cancer Res. 2009 Dec 1;15(23):7119-23.

17.Frank-Raue K, Rondot S, Raue F. Molecular genetics and phenomics of RET mutations: Impact on prognosis of MTC. Mol Cell Endocrinol. 2010 Jun 30;322(1-2):2-7.

18.Namba H, Rubin SA, Fagin JA. Point mutations of ras oncogenes are an early event in thyroid tumorigenesis. Mol Endocrinol. 1990 Oct;4(10):1474-9.

19.Esapa CT, Johnson SJ, Kendall-Taylor P, Lennard TW, Harris PE. Prevalence of Ras mutations in thyroid neoplasia. Clin Endocrinol (Oxf). 1999 Apr;50(4):529-35.

20.Kimura ET, Nikiforova MN, Zhu Z, Knauf JA, Nikiforov YE, Fagin JA. High prevalence of BRAF mutations in thyroid cancer: genetic evidence for constitutive activation of the RET/PTC-RAS-BRAF signaling pathway in papillary thyroid carcinoma. Cancer Res. 2003 Apr 1;63(7):1454-7.

21.Caronia LM, Phay JE, Shah MH. Role of BRAF in thyroid oncogenesis. Clin Cancer Res. 2011 Dec 15;17(24):7511-7.

22. Oler G, Cerutti JM. High prevalence of BRAF mutation in a Brazilian cohort of patients with sporadic papillary thyroid carcinomas: correlation with more aggressive phenotype and decreased expression of iodide-metabolizing genes. Cancer. 2009 Mar 1;115(5):972-80.

23.Wan PT, Garnett MJ, Roe SM, Lee S, Niculescu-Duvaz D, Good VM, et al. Mechanism of activation of the RAF-ERK signaling pathway by oncogenic mutations of B-RAF. Cell. 2004 Mar 19;116(6):855-67.

24.Ricarte-Filho JC, Ryder M, Chitale DA, Rivera M, Heguy A, Ladanyi M, et al. Mutational profile of advanced primary and metastatic radioactive iodine-refractory thyroid cancers reveals distinct pathogenetic roles for BRAF, PIK3CA, and AKT1. Cancer Res. 2009 Jun 1;69(11):4885-93.

25.Saji M, Ringel MD. The PI3K-Akt-mTOR pathway in initiation and progression of thyroid tumors. Mol Cell Endocrinol. 2010 May 28;321(1):20-8. 
26.Faustino A, Couto JP, Populo H, Rocha AS, Pardal F, Cameselle-Teijeiro JM, et al. mTOR pathway overactivation in BRAF mutated papillary thyroid carcinoma. J Clin Endocrinol Metab. 2012 Jul;97(7):E1139-49.

27.Bray SJ. Notch signalling: a simple pathway becomes complex. Nat Rev Mol Cell Biol. 2006 Sep;7(9):678-89.

28.Morgan T. The theory of the gene. The American Naturalist. 1917;51:513-44.

29.Wharton KA, Johansen KM, Xu T, Artavanis-Tsakonas S. Nucleotide sequence from the neurogenic locus notch implies a gene product that shares homology with proteins containing EGF-like repeats. Cell. 1985 Dec;43(3 Pt 2):567-81.

30.Kovall RA. Structures of CSL, Notch and Mastermind proteins: piecing together an active transcription complex. Curr Opin Struct Biol. 2007 Feb;17(1):117-27.

31.Kopan $\mathrm{R}$, llagan MX. The canonical Notch signaling pathway: unfolding the activation mechanism. Cell. 2009 Apr 17;137(2):216-33.

32.Nickoloff BJ, Osborne BA, Miele L. Notch signaling as a therapeutic target in cancer: a new approach to the development of cell fate modifying agents. Oncogene. $2003 \mathrm{Sep}$ 29;22(42):6598-608.

33.Iso T, Kedes L, Hamamori Y. HES and HERP families: multiple effectors of the Notch signaling pathway. J Cell Physiol. 2003 Mar;194(3):237-55.

34.Stahl M, Ge C, Shi S, Pestell RG, Stanley P. Notch1-induced transformation of RKE1 cells requires up-regulation of cyclin D1. Cancer Res. 2006 Aug 1;66(15):7562-70.

35.Huenniger K, Kramer A, Soom M, Chang I, Kohler M, Depping R, et al. Notch1 signaling is mediated by importins alpha 3, 4, and 7. Cell Mol Life Sci. 2010 Sep;67(18):3187-96.

36.Fischer A, Gessler M. Delta-Notch--and then? Protein interactions and proposed modes of repression by Hes and Hey bHLH factors. Nucleic Acids Res. 2007;35(14):4583-96.

37.Krejci A, Bray S. Notch activation stimulates transient and selective binding of $\mathrm{Su}(\mathrm{H}) / \mathrm{CSL}$ to target enhancers. Genes Dev. 2007 Jun 1;21(11):1322-7.

38.Ellisen LW, Bird J, West DC, Soreng AL, Reynolds TC, Smith SD, et al. TAN-1, the human homolog of the Drosophila notch gene, is broken by chromosomal translocations in T lymphoblastic neoplasms. Cell. 1991 Aug 23;66(4):649-61.

39.Weng AP, Ferrando AA, Lee W, Morris JPt, Silverman LB, Sanchez-Irizarry C, et al. Activating mutations of $\mathrm{NOTCH} 1$ in human $\mathrm{T}$ cell acute lymphoblastic leukemia. Science. 2004 Oct 8;306(5694):269-71. 
40.Al-Hussaini $\mathrm{H}$, Subramanyam D, Reedijk M, Sridhar SS. Notch signaling pathway as a therapeutic target in breast cancer. Mol Cancer Ther. 2010 Jan;10(1):9-15.

41.Clementz AG, Rogowski A, Pandya K, Miele L, Osipo C. NOTCH-1 and NOTCH-4 are novel gene targets of PEA3 in breast cancer: novel therapeutic implications. Breast Cancer Res. 2011;13(3):R63.

42.Stylianou S, Clarke RB, Brennan K. Aberrant activation of notch signaling in human breast cancer. Cancer Res. 2006 Feb 1;66(3):1517-25.

43.Baia GS, Stifani S, Kimura ET, McDermott MW, Pieper RO, Lal A. Notch activation is associated with tetraploidy and enhanced chromosomal instability in meningiomas. Neoplasia. 2008 Jun;10(6):604-12.

44.Ferretti E, Tosi E, Po A, Scipioni A, Morisi R, Espinola MS, et al. Notch signaling is involved in expression of thyrocyte differentiation markers and is down-regulated in thyroid tumors. J Clin Endocrinol Metab. 2008 Oct;93(10):4080-7.

45.Park HS, Jung CK, Lee SH, Chae BJ, Lim DJ, Park WC, et al. Notch1 receptor as a marker of lymph node metastases in papillary thyroid cancer. Cancer Sci. 2012 Feb;103(2):305-9.

46.Chen J, Kesari S, Rooney C, Strack PR, Shen H, Wu L, et al. Inhibition of notch signaling blocks growth of glioblastoma cell lines and tumor neurospheres. Genes Cancer. 2010 Aug;1(8):822-35.

47.Vasko V, Espinosa AV, Scouten W, He H, Auer H, Liyanarachchi S, et al. Gene expression and functional evidence of epithelial-to-mesenchymal transition in papillary thyroid carcinoma invasion. Proc Natl Acad Sci U S A. 2007 Feb 20;104(8):2803-8.

48.Weijzen S, Rizzo P, Braid M, Vaishnav R, Jonkheer SM, Zlobin A, et al. Activation of Notch-1 signaling maintains the neoplastic phenotype in human Ras-transformed cells. Nat Med. 2002 Sep;8(9):979-86.

49.Fitzgerald $\mathrm{K}$, Harrington A, Leder $\mathrm{P}$. Ras pathway signals are required for notchmediated oncogenesis. Oncogene. 2000 Aug 31;19(37):4191-8.

50.Zeng Q, Li S, Chepeha DB, Giordano TJ, Li J, Zhang H, et al. Crosstalk between tumor and endothelial cells promotes tumor angiogenesis by MAPK activation of Notch signaling. Cancer Cell. 2005 Jul;8(1):13-23.

51.Miyamoto Y, Maitra A, Ghosh B, Zechner U, Argani P, lacobuzio-Donahue CA, et al. Notch mediates TGF alpha-induced changes in epithelial differentiation during pancreatic tumorigenesis. Cancer Cell. 2003 Jun;3(6):565-76.

52.Maraver A, Fernandez-Marcos PJ, Herranz D, Canamero M, Munoz-Martin M, Gomez-Lopez G, et al. Therapeutic Effect of gamma-Secretase Inhibition in 
Kras(G12V)-Driven Non-Small Cell Lung Carcinoma by Derepression of DUSP1 and Inhibition of ERK. Cancer Cell. 2012 Aug 14;22(2):222-34.

53.Fusco A, Berlingieri MT, Di Fiore PP, Portella G, Grieco M, Vecchio G. One- and twostep transformations of rat thyroid epithelial cells by retroviral oncogenes. Mol Cell Biol. 1987 Sep;7(9):3365-70.

54.Saavedra HI, Knauf JA, Shirokawa JM, Wang J, Ouyang B, Elisei R, et al. The RAS oncogene induces genomic instability in thyroid PCCL3 cells via the MAPK pathway. Oncogene. 2000 Aug 10;19(34):3948-54.

55.Ricarte-Filho JC, Fuziwara CS, Yamashita AS, Rezende E, da-Silva MJ, Kimura ET. Effects of let-7 microRNA on Cell Growth and Differentiation of Papillary Thyroid Cancer. Transl Oncol. 2009 Dec;2(4):236-41.

56.Wang J, Knauf JA, Basu S, Puxeddu E, Kuroda H, Santoro M, et al. Conditional expression of RET/PTC induces a weak oncogenic drive in thyroid PCCL3 cells and inhibits thyrotropin action at multiple levels. Mol Endocrinol. 2003 Jul;17(7):1425-36.

57.Tanaka J, Ogura T, Sato H, Hatano M. Establishment and biological characterization of an in vitro human cytomegalovirus latency model. Virology. 1987 Nov;161(1):62-72.

58.Fabien N, Fusco A, Santoro M, Barbier Y, Dubois PM, Paulin C. Description of a human papillary thyroid carcinoma cell line. Morphologic study and expression of tumoral markers. Cancer. 1994 Apr 15;73(8):2206-12.

59.Gossen M, Bujard $\mathrm{H}$. Tight control of gene expression in mammalian cells by tetracycline-responsive promoters. Proc Natl Acad Sci U S A. 1992 Jun 15;89(12):554751.

60.Mosmann T. Rapid colorimetric assay for cellular growth and survival: application to proliferation and cytotoxicity assays. J Immunol Methods. 1983 Dec 16;65(1-2):55-63.

61.Pfaffl MW. A new mathematical model for relative quantification in real-time RT-PCR. Nucleic Acids Res. 2001 May 1;29(9):e45.

62.Simon P. Q-Gene: processing quantitative real-time RT-PCR data. Bioinformatics. 2003 Jul 22;19(11):1439-40.

63.Towbin H, Staehelin T, Gordon J. Electrophoretic transfer of proteins from polyacrylamide gels to nitrocellulose sheets: procedure and some applications. Proc Natl Acad Sci U S A. 1979 Sep;76(9):4350-4.

64.Knauf JA, Ma X, Smith EP, Zhang L, Mitsutake N, Liao XH, et al. Targeted expression of BRAFV600E in thyroid cells of transgenic mice results in papillary thyroid cancers that undergo dedifferentiation. Cancer Res. 2005 May 15;65(10):4238-45. 
65.Matsuo SE, Fiore AP, Siguematu SM, Ebina KN, Friguglietti CU, Ferro MC, et al. Expression of SMAD proteins, TGF-beta/activin signaling mediators, in human thyroid tissues. Arq Bras Endocrinol Metabol. 2010 Jun;54(4):406-12.

66.Ryder M, Ghossein RA, Ricarte-Filho JC, Knauf JA, Fagin JA. Increased density of tumor-associated macrophages is associated with decreased survival in advanced thyroid cancer. Endocr Relat Cancer. 2008 Dec;15(4):1069-74.

67.Radtke F, Raj K. The role of Notch in tumorigenesis: oncogene or tumour suppressor? Nat Rev Cancer. 2003 Oct;3(10):756-67.

68.Ranganathan $\mathrm{P}$, Weaver $\mathrm{KL}$, Capobianco AJ. Notch signalling in solid tumours: a little bit of everything but not all the time. Nat Rev Cancer. 2011 May;11(5):338-51.

69.Santagata S, Demichelis F, Riva A, Varambally S, Hofer MD, Kutok JL, et al. JAGGED1 expression is associated with prostate cancer metastasis and recurrence. Cancer Res. 2004 Oct 1;64(19):6854-7.

70.Chu D, Li Y, Wang W, Zhao Q, Li J, Lu Y, et al. High level of Notch1 protein is associated with poor overall survival in colorectal cancer. Ann Surg Oncol. 2010 May;17(5):1337-42.

71.Jhiang SM, Sagartz JE, Tong Q, Parker-Thornburg J, Capen CC, Cho JY, et al. Targeted expression of the ret/PTC1 oncogene induces papillary thyroid carcinomas. Endocrinology. 1996 Jan;137(1):375-8.

72.Santoro M, Chiappetta G, Cerrato A, Salvatore D, Zhang L, Manzo G, et al. Development of thyroid papillary carcinomas secondary to tissue-specific expression of the RET/PTC1 oncogene in transgenic mice. Oncogene. 1996 Apr 18;12(8):1821-6.

73.Chakravarty D, Santos E, Ryder M, Knauf JA, Liao XH, West BL, et al. Smallmolecule MAPK inhibitors restore radioiodine incorporation in mouse thyroid cancers with conditional BRAF activation. J Clin Invest. 2011 Dec;121(12):4700-11.

74.Charles RP, lezza G, Amendola E, Dankort D, McMahon M. Mutationally activated BRAF(V600E) elicits papillary thyroid cancer in the adult mouse. Cancer Res. 2011 Jun 1;71(11):3863-71.

75.Franco AT, Malaguarnera R, Refetoff S, Liao XH, Lundsmith E, Kimura S, et al. Thyrotrophin receptor signaling dependence of Braf-induced thyroid tumor initiation in mice. Proc Natl Acad Sci U S A. 2011 Jan 25;108(4):1615-20.

76.Mesa C, Jr., Mirza M, Mitsutake N, Sartor M, Medvedovic M, Tomlinson C, et al. Conditional activation of RET/PTC3 and BRAFV600E in thyroid cells is associated with gene expression profiles that predict a preferential role of BRAF in extracellular matrix remodeling. Cancer Res. 2006 Jul 1;66(13):6521-9. 
77.Palona I, Namba H, Mitsutake N, Starenki D, Podtcheko A, Sedliarou I, et al. BRAFV600E promotes invasiveness of thyroid cancer cells through nuclear factor kappaB activation. Endocrinology. 2006 Dec;147(12):5699-707.

78.Cassinelli G, Favini E, Degl'Innocenti D, Salvi A, De Petro G, Pierotti MA, et al. RET/PTC1-driven neoplastic transformation and proinvasive phenotype of human thyrocytes involve Met induction and beta-catenin nuclear translocation. Neoplasia. 2009 Jan;11(1):10-21.

79.Bizhanova A, Kopp P. Minireview: The sodium-iodide symporter NIS and pendrin in iodide homeostasis of the thyroid. Endocrinology. 2009 Mar;150(3):1084-90.

80.Riesco-Eizaguirre G, Rodriguez I, De la Vieja A, Costamagna E, Carrasco N, Nistal $\mathrm{M}$, et al. The BRAFV600E oncogene induces transforming growth factor beta secretion leading to sodium iodide symporter repression and increased malignancy in thyroid cancer. Cancer Res. 2009 Nov 1;69(21):8317-25.

81.Capobianco AJ, Zagouras P, Blaumueller CM, Artavanis-Tsakonas S, Bishop JM. Neoplastic transformation by truncated alleles of human NOTCH1/TAN1 and NOTCH2. Mol Cell Biol. 1997 Nov;17(11):6265-73.

82.Sharma VM, Draheim KM, Kelliher MA. The Notch1/c-Myc pathway in T cell leukemia. Cell Cycle. 2007 Apr 15;6(8):927-30.

83.Weijzen S, Zlobin A, Braid M, Miele L, Kast WM. HPV16 E6 and E7 oncoproteins regulate Notch-1 expression and cooperate to induce transformation. J Cell Physiol. 2003 Mar;194(3):356-62.

84.Palomero T, Lim WK, Odom DT, Sulis ML, Real PJ, Margolin A, et al. NOTCH1 directly regulates c-MYC and activates a feed-forward-loop transcriptional network promoting leukemic cell growth. Proc Natl Acad Sci U S A. 2006 Nov 28;103(48):182616.

85.Noseda M, Niessen K, McLean G, Chang L, Karsan A. Notch-dependent cell cycle arrest is associated with downregulation of minichromosome maintenance proteins. Circ Res. 2005 Jul 22;97(2):102-4.

86.Devgan V, Mammucari C, Millar SE, Brisken C, Dotto GP. p21WAF1/Cip1 is a negative transcriptional regulator of Wnt4 expression downstream of Notch1 activation. Genes Dev. 2005 Jun 15;19(12):1485-95.

87.Rasul S, Balasubramanian R, Filipovic A, Slade MJ, Yague E, Coombes RC. Inhibition of gamma-secretase induces G2/M arrest and triggers apoptosis in breast cancer cells. Br J Cancer. 2009 Jun 16;100(12):1879-88. 
88.Wang Z, Zhang Y, Li Y, Banerjee S, Liao J, Sarkar FH. Down-regulation of Notch-1 contributes to cell growth inhibition and apoptosis in pancreatic cancer cells. Mol Cancer Ther. 2006 Mar;5(3):483-93.

89.Curry CL, Reed LL, Broude E, Golde TE, Miele L, Foreman KE. Notch inhibition in Kaposi's sarcoma tumor cells leads to mitotic catastrophe through nuclear factor-kappaB signaling. Mol Cancer Ther. 2007 Jul;6(7):1983-92.

90.Aziz K, Nowsheen S, Pantelias G, lliakis G, Gorgoulis VG, Georgakilas AG. Targeting DNA damage and repair: embracing the pharmacological era for successful cancer therapy. Pharmacol Ther. 2012 Mar;133(3):334-50.

91.Castedo M, Perfettini JL, Roumier T, Kroemer G. Cyclin-dependent kinase-1: linking apoptosis to cell cycle and mitotic catastrophe. Cell Death Differ. 2002 Dec;9(12):128793.

92.Vitale I, Galluzzi L, Castedo M, Kroemer G. Mitotic catastrophe: a mechanism for avoiding genomic instability. Nat Rev Mol Cell Biol. 2011 Jun;12(6):385-92.

93.Rizzo P, Miao H, D'Souza G, Osipo C, Song LL, Yun J, et al. Cross-talk between notch and the estrogen receptor in breast cancer suggests novel therapeutic approaches. Cancer Res. 2008 Jul 1;68(13):5226-35.

94.Fassl A, Tagscherer KE, Richter J, Berriel Diaz M, Alcantara Llaguno SR, Campos B, et al. Notch1 signaling promotes survival of glioblastoma cells via EGFR-mediated induction of anti-apoptotic Mcl-1. Oncogene. 2012 Jan 16.

95.Rosati E, Sabatini R, De Falco F, Del Papa B, Falzetti F, Di lanni M, et al. gammaSecretase inhibitor I induces apoptosis in chronic lymphocytic leukemia cells by proteasome inhibition, endoplasmic reticulum stress increase and notch downregulation. Int J Cancer. 2012 Sep 24.

96.Bollag G, Tsai J, Zhang J, Zhang C, Ibrahim P, Nolop K, et al. Vemurafenib: the first drug approved for BRAF-mutant cancer. Nat Rev Drug Discov. 2012 Nov;11(11):873-86.

97.Moellering RE, Cornejo M, Davis TN, Del Bianco C, Aster JC, Blacklow SC, et al. Direct inhibition of the NOTCH transcription factor complex. Nature. 2009 Nov 12;462(7270):182-8.

98.Aster JC, Blacklow SC. Targeting the Notch pathway: twists and turns on the road to rational therapeutics. J Clin Oncol. 2012 Jul 1;30(19):2418-20.

99.Trusolino L, Bertotti A. Compensatory pathways in oncogenic kinase signaling and resistance to targeted therapies: six degrees of separation. Cancer Discov. 2012 Oct;2(10):876-80. 
100.Al-Lazikani B, Banerji U, Workman P. Combinatorial drug therapy for cancer in the post-genomic era. Nat Biotechnol. 2012 Jul;30(7):679-92.

101.Olaussen KA, Commo F, Tailler M, Lacroix L, Vitale I, Raza SQ, et al. Synergistic proapoptotic effects of the two tyrosine kinase inhibitors pazopanib and lapatinib on multiple carcinoma cell lines. Oncogene. 2009 Dec 3;28(48):4249-60.

102.Tolcher AW, Messersmith WA, Mikulski SM, Papadopoulos KP, Kwak EL, Gibbon DG, et al. Phase I study of RO4929097, a gamma secretase inhibitor of Notch signaling, in patients with refractory metastatic or locally advanced solid tumors. J Clin Oncol. 2012 Jul 1;30(19):2348-53. 